\title{
THE EFFECTS OF PROTECTIVE FOOTWEAR ON SPINE CONTROL AND LIFTING MECHANICS
}

\author{
Matthew Mavor
}

\begin{abstract}
A thesis submitted in partial fulfillment of the requirements for the M.Sc. degree in Human Kinetics
\end{abstract}

\author{
School of Human Kinetics \\ Faculty of Health Science \\ University of Ottawa
}

(C) Matthew Mavor, Ottawa, Canada, 2018 


\section{Table of Contents}

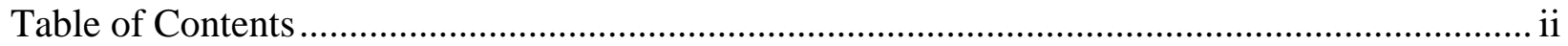

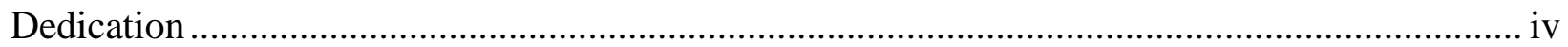

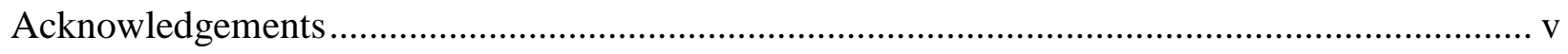

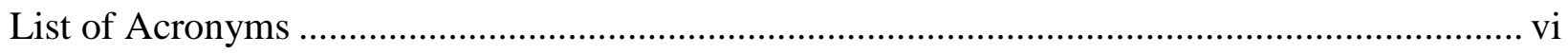

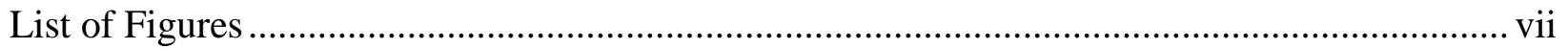

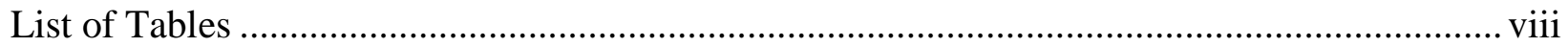

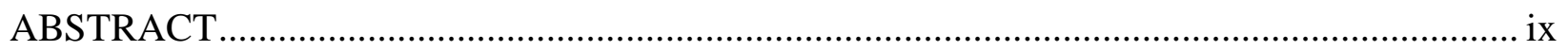

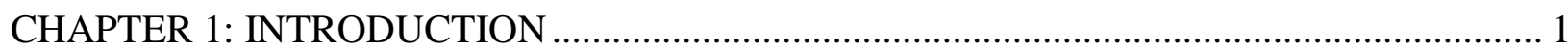

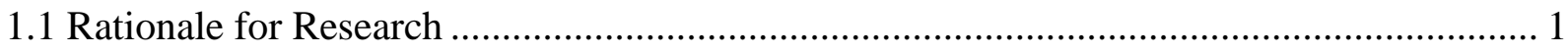

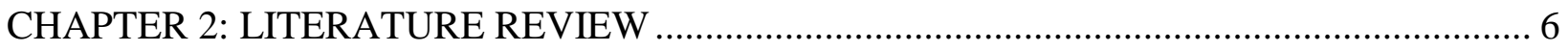

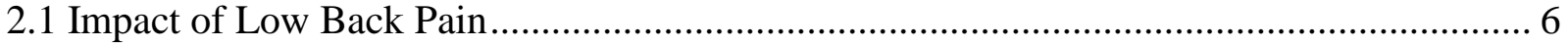

2.2 Manual Materials Handling ..................................................................................... 7

2.3 Risk Factors for the Development of Low Back Pain................................................ 9

2.4 Determining the Risk of Developing Low Back Pain/Injury ........................................ 12

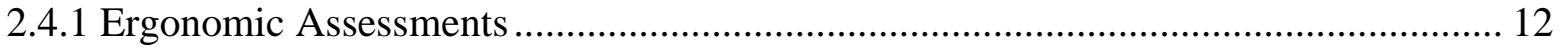

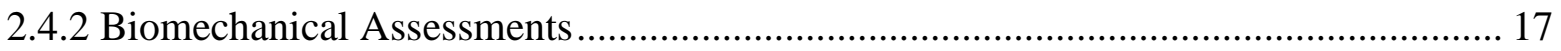

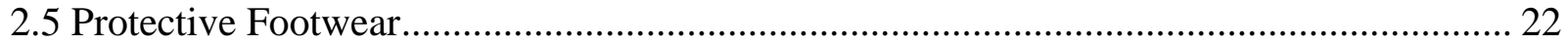

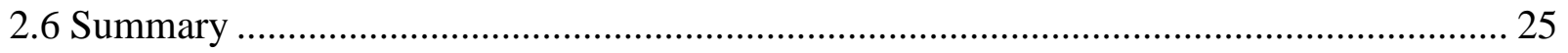

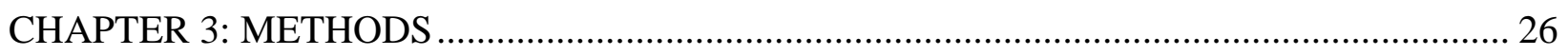

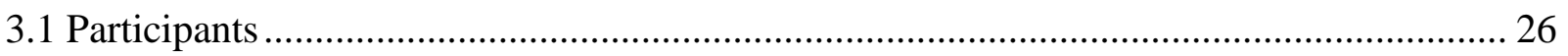

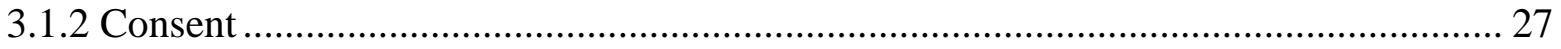

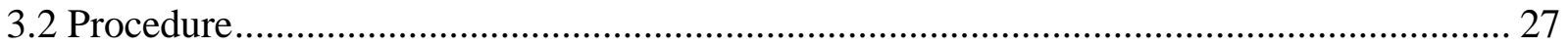

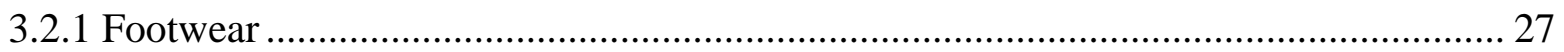

3.2.2 Determining Maximum Back Strength........................................................... 28

3.2.3 Participant Preparation and Equipment .............................................................. 29

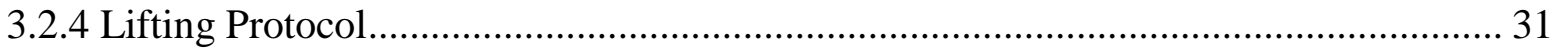

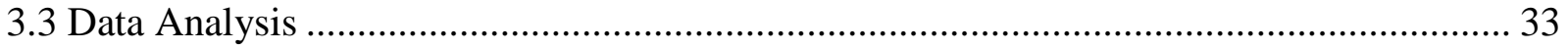

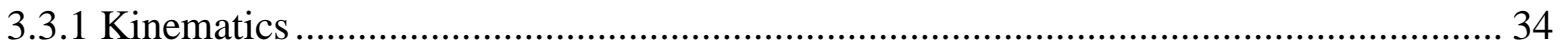

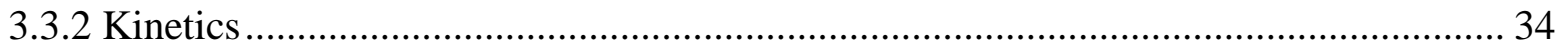

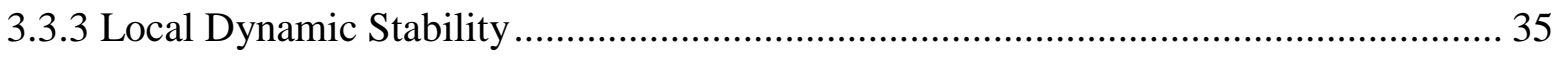

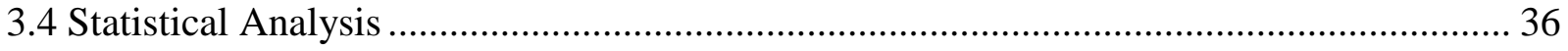




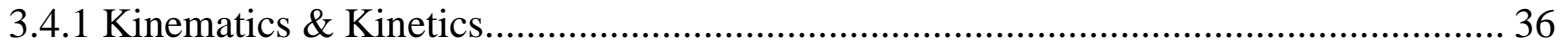

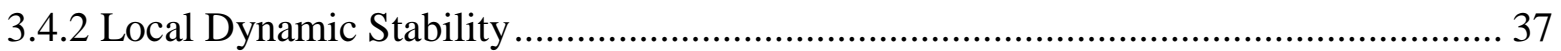

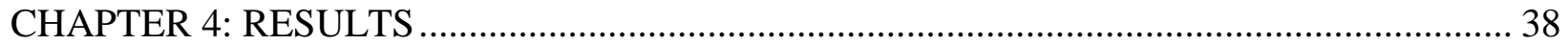

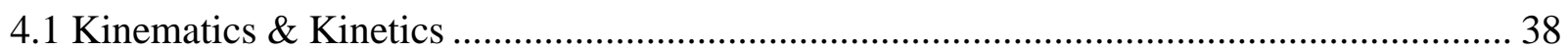

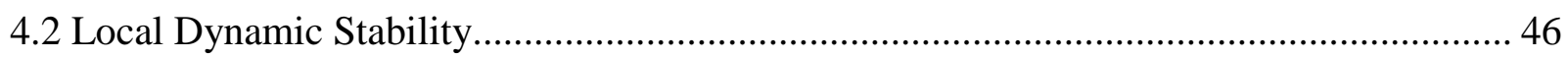

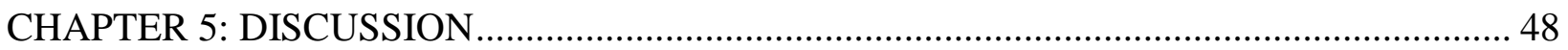

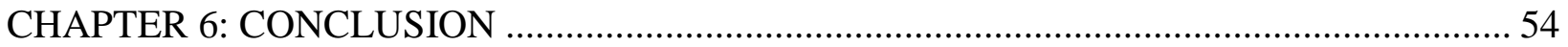

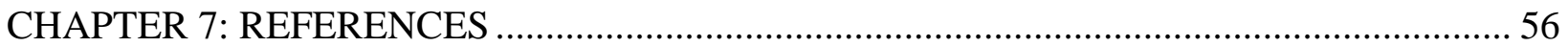

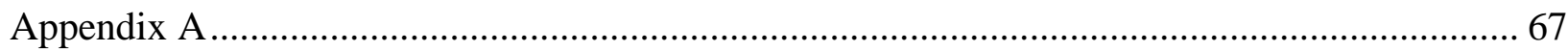

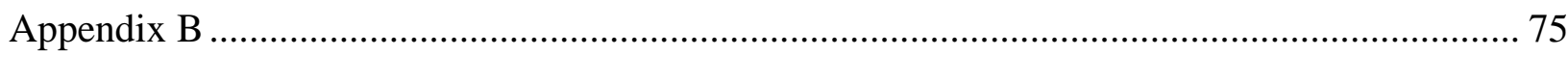

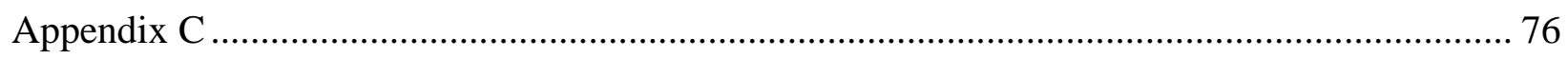

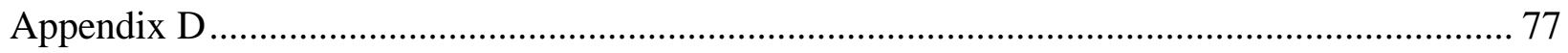




\section{Dedication}

I would like to dedicate this thesis to the memory of my father David Mavor. My father was a very influential person in my life whose back issues are what drove me towards spine research. His teachings of hard work and dedication are what helped mold me into the person I am today. Unfortunately, my father passed away after a long and courageous battle with pancreatic cancer days before the final draft of this paper was completed. Dad, I cherished every extra moment I got to spend with you over your final months, and I will continue to make you proud. Although, I never got the opportunity to help you through my research, I hope that many others who suffer from similar ailments will be positively impacted by the research my team and many others around the world are continuously working towards. 


\section{Acknowledgements}

Many great people helped me throughout my master's work who deserve my recognition. Some helped me formulate my main idea, others helped with data collection, an unlucky few read and edited this thesis, and others were with me throughout the entire process. All of these people helped make this thesis what it is today and kept me sane throughout.

First, I would like to thank my supervisor, Dr. Ryan Graham. Words cannot express how much gratitude and respect I have towards Ryan. He recognized my potential as an undergraduate student and pushed me to pursue higher education. The knowledge and experiences Ryan has given me are invaluable and will shape who I will become far into the future. Thank you, Ryan, for all your support you have given me throughout the years.

Second, I would like to thank my family. They have supported me throughout my studies and were always there to offer words of encouragement and motivation. Specifically, I would like to give my greatest thanks to my father, David. From a young age, he taught me the meaning of hard work and built a work ethic in me like none other. It was his low back injury that had peaked my interest in spine biomechanics and his words of encouragement that got me through to the end.

Third, I would like to thank my lab mates who helped me during the data collection and editing process. Eric, Mohammad, Gwyneth, Kristen, Tianna, and Wantuir Jr., I will always cherish our lab outings, intense nerdy biomechanical talks, and our lunch-time card games. I wish you all the best of luck in this crazy journey we call life. Thank you all for being my friends.

Finally, I would like to thank my long-time girlfriend, Samantha. Sam has been my rock throughout this entire process. She has been there for all the ups and downs, listened to every detail of my project, and has listened to every presentation that I made (several times). Thank you for everything I've put you through. I love you. 


\section{List of Acronyms}

$\lambda_{\max } \quad$ Maximum finite-time Lyapunov exponent

2D Two-dimensional

3D Three-dimensional

ACGIH- American Conference of Governmental Industrial Hygienists Lifting Threshold Lifting TLV Limit Values

ASTM American Society for Testing and Materials

ANOVA Analysis of Variance

CLI Composite Lifting Index

CNS Central Nervous System

CSA Canadian Standards Association

EMG Electromyography

GCS Global Coordinate System

$\mathbf{L}_{4} / \mathbf{L}_{5} \quad$ Lumbar 4 and Lumbar 5 Intervertebral Joint

LBP Low Back Pain

LCS Local Coordinate System

LDS Local Dynamic Stability

LI Lifting Index

LSD Least Significant Difference

MAC tool Manual Handling Assessment Charts

MAWL Maximum Acceptable Weight Limit

MET Metatarsal Guard

MMH Manual Materials Handling

MVC Maximal Voluntary Contraction

NIOSH National Institute for Occupational Safety and Health

NLE NIOSH Lifting Equation

PPE Personal Protective Equipment

ROM Range of Motion

RWL Recommended Weight Limit

SD Standard Deviation

SLI Sequential Lifting Index

WSIB Workplace Safety and Insurance Board of Ontario 


\section{List of Figures}

Figure 1. Protective Footwear Conditions .......................................................................... 28

Figure 2. Setup for Determining Maximum Back Strength ................................................ 29

Figure 3. Visual Representation of the Lifting Task........................................................... 33

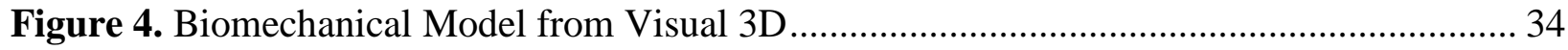

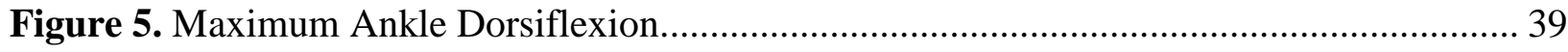

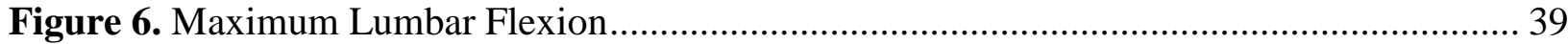

Figure 7. Maximum Sagittal Net Reaction Moments about the Low Back .............................. 40

Figure 8. Low Back Local Dynamic Stability Results...................................................... 46

Figure 9. Upper Back Local Dynamic Stability Results .................................................. 47

Figure 10. Kinematic Chain Dynamic Stability Results ................................................... 48

Figure B1. Marker placement to track the feet in work boots. ........................................... 75

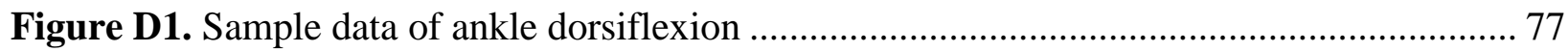

Figure D2. Sample data of low back flexion angles ........................................................ 77

Figure D3. Sample data of low back sagittal moments........................................................ 78 


\section{List of Tables}

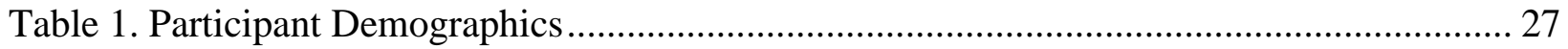

Table 2. Sagittal Plane Kinematic Results ......................................................................... 41

Table 3. Transverse Plane Kinematic Results........................................................................ 42

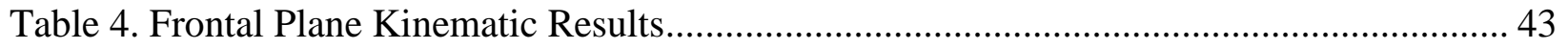

Table 5. Low Back Kinematic Results .............................................................................. 44

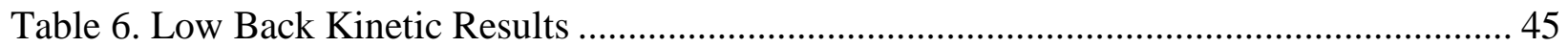

Table 7. Lower and Upper Back Local Dynamic Stability Results ....................................... 47 


\begin{abstract}
Low back pain (LBP) is a common condition that affects all age groups and sexes. Although the development of LBP is multifactorial, the performance of lifting-based manual material handling $(\mathrm{MMH})$ tasks are recognized as a primary risk factor. Many occupations that involve $\mathrm{MMH}$ tasks are performed in hazardous environments, where personal protective equipment (PPE) must be worn. Among the most commonly prescribed forms of PPE in Canada are CSA Grade 1 steel-toed work boots. According to the hazards present on the jobsite, workers may need to wear steel-toed work boots with/without a metatarsal guard or be able to wear steeltoed shoes (no upper). However, the amount of research on the interaction between protective footwear and human motion is limited. Therefore, the purpose of this thesis was to assess the effects of steel-toed shoes (unlaced), steel-toed boots (work boot), and steel-toed boots with a metatarsal guard (MET) on lifting mechanics. Specifically, three-dimensional kinematics of the lower limbs and trunk, sagittal net reaction moments of the low back, and local dynamic stability (LDS) of the lower limbs, lower back, and upper back were analyzed. Twelve males and 12 females were recruited to participate in this research project. Participants performed a repetitive lifting task at $10 \%$ of their maximum back strength, under three block-randomized footwear conditions. Ankle dorsiflexion was negatively affected by footwear type, where dorsiflexion was reduced the most in the MET condition compared to the unlaced condition $(p<0.01)$. However, there were no other main effects of footwear type on any other variable tested, and both male and female participants were able to maintain similar lifting mechanics and LDS values when moving up the kinematic chain. It is possible that participants were able to preserve their kinematics and stability through the appropriate recruitment of muscles, which may have implications for an increase in compressive and shear force on the spine and should be explored further in the future.
\end{abstract}




\section{CHAPTER 1: INTRODUCTION}

\subsection{Rationale for Research}

Workplace injuries are common events that affect all age groups, occupations, and sexes. In 2016, the Workplace Safety and Insurance Board of Ontario (WSIB) approved approximately 57,000 lost-time claims, $17 \%$ of which were injuries to the low back (WSIB, 2016). Low back injuries (i.e. a sprain or strain, which can lead to low back pain (LBP)) have been the most commonly reported workplace injury across all industry types in Ontario since 2005, affecting both male and female workers 25-64 years old (WSIB, 2016). On a global scale, LBP has been identified as the number one cause for years lived with a disability in 139 out of the 188 countries studied (Global Burden of Disease Study 2013 Collaborators, 2015). This high prevalence of LBP results in enormous medical and economic costs. It is estimated that the medical expenditures for LBP in Canada range from 6 to 12 billion dollars per year, in addition to the tremendous strain that lost time and productivity puts on the economy (Bone and Joint Canada, 2017). In 2016, an average of 7.7 days of work were lost within one month following a workplace injury, and an average of 14.1 working days were lost within three months post workplace injury (WSIB, 2016). Given the large global prevalence of LBP and the multitude of associated costs, it is critical to understand possible mechanistic and environmental factors that can lead to the development of LBP.

Manual materials handling (MMH) tasks are very common in workplaces. Lifting-based MMH tasks are among the most commonly performed tasks in industry and have been identified as a major risk factor for the development of LBP (e.g. da Costa \& Vieira, 2010). Da Costa and Vieira (2010) reported that the top biomechanical risk factors for the development of LBP are heavy physical work and awkward working postures. When performing MMH tasks, the weight of the object and the muscular contractions necessary to stiffen the spine and drive trunk movements introduce additional loads on the spine (Davis \& Marras, 2000). 
Depending on the task demands, these spinal loads can become very large when lifting heavy objects, leading to vertebral endplate fractures (van Dieën, Weinans, \& Toussaint, 1999). Alternatively, spinal loads can be small and repetitive, exposing the supportive tissues to cumulative loading, which leads to an accumulation of microdamage, ultimately weakening their force-bearing capacity (Marras, Ferguson, Lavender, Splittstoesser, \& Yang, 2014). Some working environments restrict the postures available to the worker (e.g. underground mining), thus forcing the adoption of a more flexed posture, which increases the loads on the spine while lifting (Hoozemans, Kingma, de Vries, \& van Dieën, 2008; Lavender, Andersson, Schipplein, \& Fuentes, 2003). Prolonged trunk flexion will also induce viscoelastic deformation (i.e. creep) into the supportive tissues of the back (Hoogendoorn et al., 2000), ultimately reducing the passive stiffness of the spine (McGill \& Brown, 1992; Toosizadeh, 2013). In addition to spinal loads, the lifter must also attenuate constant perturbations to their equilibrium caused by an altered centre of mass (Kollmitzer, Oddsson, Ebenbichler, Giphart, \& De Luca, 2002), muscular contractions and neural control errors (Panjabi, 1992a). This can become even more taxing on the lifter if they are in environments with poor temperature control, possibly inducing heat/cold stress on the lifter, which can lead to neuromuscular impairments (Racinais \& Oksa, 2010). Furthermore, lifting in environments that have unstable/slippery floors can cause large global perturbations (e.g. Beaudette, Graham, \& Brown, 2014), which, unless controlled for, can lead to falling (Park, Singh, Huston, \& Song, 2008) or an unsuccessful transmission of spinal loads (Cholewicki \& McGill, 1996; Panjabi, 1992b). Therefore, it is important to assess where and how an individual lifts, in addition to the load itself.

A common way to assess how risky a job is to the worker's overall health is to do an ergonomic assessment. Ergonomic assessment tools are designed to quantify and predict exposure 
to loads on the human muscular and cardiorespiratory systems (Dempsey, 1998; Russell, Winnemuller, Camp, \& Johnson, 2007). Ergonomic assessments are performed in the field; however, workplace tasks can also be simulated in the laboratory. Simulating a task in the laboratory allows biomechanists and ergonomists to further investigate possible mechanistic factors that can lead to the development of LBP (e.g. Gregory, Laughton, Carman, Milosavljevic, \& Callaghan, 2009; Mc Kinnon, Callaghan, \& Dickerson, 2011). Using tools such as motion capture, electromyography (EMG), force plates, and musculoskeletal models, biomechanists can estimate the moments and forces on the spine, evaluate muscle function, and calculate joint angles, to which various mathematical analyses can be applied (e.g. dynamic systems, wavelet coherence; Robertson, Caldwell, Hamill, Kamen, \& Whittlesey, 2014). Although many MMH ergonomic assessments (e.g. Mac-tool, NIOSH lifting equation) do include variables for lifting posture, repetition, object mass, and environmental factors, to date, none include mandatory workwear (e.g. steel-toed work boots) as a possible risk factor for LBP.

To protect workers from the many hazards that are present in the workplace (e.g. falling objects, movement of heavy machinery), governments have established strict safety guidelines to protect workers. One of the most basic forms of safety regulations is the use of personal protective equipment (PPE). PPE are wearable devices that mitigate a variety of safety concerns in the workplace; most commonly, these include hi-visibility vests, protective gloves, safety glasses, hard hats, and steel-toed work boots (R.R.O. 1990, Reg. 851). Mandates for wearing each form of PPE are specific to the hazards that are present on the job site (R.R.O. 1990, Reg. 851); workers may be required to wear all the PPE mentioned above or a combination thereof.

One of the more frequently prescribed forms of PPE in Canada are Canadian Standards Association (CSA) Grade 1 work boots that protect workers' feet from crushing and puncturing 
hazards (Canadian Centre for Occupational Health and Safety, 2017). Work boots come in a variety of styles with differences in material type/stiffness, boot height, and protection grades, with mandates for footwear type varying between occupations. Occupations that put workers at a very high risk for crushing hazards may mandate that steel-toed work boots have a metatarsal guard: a metal sheath that covers the dorsum of the foot. Lower-risk occupations may only mandate steeltoed boots with no additional guards or may allow workers to wear steel-toed shoes that have no material wrapping the ankle. Differences in shoe type may be of concern since an increase in boot stiffness and weight have both been shown to negatively affect human locomotion and decrease the range of motion (ROM) of the ankle (Böhm and Hösl, 2010; Cikajlo and Matjacić, 2007). With respect to lifting tasks, work boots have also been shown to decrease ankle ROM and global trunk inclination angle (i.e. the trunk is more parallel to the floor; Blench, 1998). Given the great importance of having a stable base of support during lifting tasks (e.g. Graham et al., 2011), the restrictive nature of the work boot may also negatively impact neuromuscular control and joint stability when moving up the kinematic chain.

Although the trades and other industrious workplaces have historically been maledominated occupations, there are rising rates of women performing workplace $\mathrm{MMH}$ tasks (Statistics Canada, 2010a; Statistics Canada 2010b). Sadler, Graham, and Stevenson (2013) and Sheppard, Stevenson, and Graham (2016) found that when lifting weight is normalized to a given percentage of a participant's functional capacity (i.e. maximum back strength) that there are no differences in lifting biomechanics and technique between sexes. Additionally, there appears to be no sex differences in local dynamic stability (low back; Graham, Sadler, Stevenson, 2012) or lumbar flexion angle (Granata and Gottipati, 2008) for symmetrical lifting tasks. Despite these 
non-significant findings, it is important to consider and confirm whether males and females are differentially affected by changes in footwear during lifting-based MMH tasks.

Although lifting is a very common task in industry, few researchers have looked at how occupational constraints (e.g. work boots) affect occupational tasks. The only such research focuses on gait (i.e. Böhm \& Hösl, 2010; Cikajlo \& Matjacić, 2007) and only one research group has looked at work boots while lifting (i.e. Blench, 1998), and was limited to 2D kinematics and EMG. Therefore, the purpose of this thesis was to investigate the effects of protective footwear (i.e. unlaced work boots (unlaced), laced work boots (work boot) and laced work boots with a metatarsal guard (MET)) on three-dimensional trunk and lower limb biomechanics during repetitive floor to waist height lifting. Both males and females were included in the participant pool to test any sex differences between conditions. To test for any differences due to sex and/or footwear type, lower limb (i.e. ankle, knee, hip), low back, and upper back kinematics were evaluated, spinal loading was quantified using low back net reaction moments, and, as complimentary analysis, whole-body movement control was quantified using LDS going up the kinematic chain (i.e. foot, shank, thigh, pelvis, low back, upper back).

It was hypothesized that protective footwear would cause a reduction in ankle plantar/dorsiflexion ROM, where the MET condition was hypothesized to be more restrictive than the work boot condition, and the unlaced condition would be the least restrictive. The expected reduction in ankle ROM was hypothesized to result in a greater lumbar flexion angle (Beach, Frost, Clark, Maly, \& Callaghan, 2014), which would lead to an increase in sagittal net reaction moments about the low back (Hoozemans et al., 2008), where the MET condition would produce the greatest moments and the unlaced condition would produce the lowest. The hypothesized change in trunk kinematics was also hypothesized to negatively impact LDS in the lower and upper back segments 
(i.e. increase $\lambda_{\max }$ ). It was further hypothesized that LDS estimates would be impaired at each body segment going up the kinematic chain; however, the largest change was expected to be at the level of the lower and upper back (Graham et al., 2011).

\section{CHAPTER 2: LITERATURE REVIEW}

\subsection{Impact of Low Back Pain}

LBP is a common condition that affects all age groups and sexes, regardless of nationality or socioeconomic status. It is estimated that approximately $75 \%$ of adults will experience LBP at least once in their adult life (Majid \& Truumees, 2008), with yearly incidences of 22-65\% of the population (Walker, 2000). In Ontario, injuries to the low back (e.g. a sprain or strain, which can then lead to LBP), have been the most reported workplace injury since 2005 for both male and female workers 25-64 years old, employed in all industry types. In 2016, injuries to the low back accounted for $17 \%$ of the 57,000 lost time claims approved by the Workplace Safety and Insurance Board of Ontario (WSIB, By the Numbers 2016). Globally, it is estimated that $10 \%$ of the world's population currently lives with LBP, making it the number one cause for years living with a disability in 45 out of 50 developed countries and 94 out of 138 developing countries (Global Burden of Disease Study 2013 Collaborators, 2015).

The high prevalence of LBP puts an enormous economic burden on the host country. In Canada, it is estimated that annual medical costs for LBP are between 6 and 12 billion dollars (Bone and Joint Canada). In the United States, LBP is estimated to cost their economy more than $\$ 100$ billion annually, approximately two-thirds of which is attributable to indirect costs (Katz, 2006). LBP does not only interfere with the health care system, but also affects the economy through lost working days. In Ontario, across all musculoskeletal injury types, workers are off work for an average of 7.7 days in the first month following injury and are off work on average 
14.1 days within the three months post injury (WSIB, By the Numbers 2016). When time is taken off work, workers can no longer earn an income; therefore, for those covered by WSIB, they are compensated for their lost wages. In 2016, this resulted in $\$ 856$ million being paid to injured workers who filed a lost time claim, $17 \%$ of which were due to low back injuries.

\subsection{Manual Materials Handling}

MMH tasks are those where an individual transfers objects or people/animals from one location to another, typically through lifting, lowering, pushing, pulling, or carrying (Dempsey, 1998). MMH tasks are very common in workplaces and are regarded as one of the largest risk factors for the development of LBP (da Costa \& Vieira, 2010). The manual handling of loads causes continuous perturbations to the lifter's equilibrium (Graham et al., 2011; Oddsson, Persson, Cresswell, \& Thorstensson, 1999) and introduces additional loads to the spine (Davis \& Marras, 2000). Both of these factors can contribute to the development of LBP through physiological (e.g. neuromuscular fatigue; Radwin, Marras, \& Lavender, 2002) and mechanical changes (e.g. tissue failure; van Dieën et al., 1999) to the human spine.

The spine is an inherently unstable structure that is made up of three subsystems: ligamentous, musculotendinous, and neural control (Panjabi, 1992a). These subsystems work together to stabilize and protect the spine from constant perturbations caused by muscular contractions and the movement of loads (Panjabi, 1992a). The central nervous system (CNS) employs the active subsystems (i.e. musculotendinous and neural control) to stiffen the spine, allowing it to bear loads (Brown \& McGill, 2010) and to provide the appropriate amount of feedback. If there were no muscles to stiffen the joints, the osteoligamentous lumbar spine would buckle under compressive loads as low as $90 \mathrm{~N}$ ( $\sim 9 \mathrm{~kg}$; Crisco, Panjabi, Yamamoto, \& Oxland, 1992). Likewise, negative feedback (force is opposite of the displacement) from the active systems needs to be larger than the positive feedback (force in the same direction as displacement) to give 
the spine a more stable behaviour (Reeves \& Cholewicki, 2013). The spine is exposed to many small, naturally occurring perturbations every day. These small "local" perturbations are the result of muscular contractions and motor control errors (Panjabi, 1992a). The healthy spine can offset these perturbations through the appropriate interaction between the ligamentous, muscular (Granata \& Marras, 2000), and neural control subsystems (Panjabi, 1992b). However, when performing $\mathrm{MMH}$ tasks, perturbations become larger by altering the individual's centre of mass which disturbs their balance and equilibrium (Graham et al., 2011; Oddsson et al., 1999). If perturbations become too large, they can lead to unsuccessful transmission of loads and ultimately to LBP or injury (Cholewicki \& McGill, 1996; Panjabi, 1992b).

When lifting loads, the weight of the object and the contraction of muscles impose forces to the lifter's spine. It is accepted that spinal loading is largely influenced by muscular force: as muscles contract to stabilize the spine and drive the lifting motion, they produce forces on the spine (Granata \& Marras, 1995; McGill, 1992; van Dieën \& Kingma, 1999). If the forces on the spine are large or repetitive in nature, they can lead to the development of injury and LBP. Large peak spinal loads can cause instantaneous tissue failure and result in the development of vertebral endplate fractures (van Dieën et al., 1999). On the other hand, repetitive exposure to small spinal loads leads to an accumulation of micro-damage in the supportive tissues, which reduces their force-bearing capacity and decreases the tissue's failure threshold (Kumar, 1990). Additionally, repetitive exposure to loading causes both the muscular and neuromuscular systems to fatigue (Radwin et al., 2002). If there is any damage to the supportive tissues or muscular/neuromuscular fatigue, it can lead to a decreased ability to control movements which may cause an impaired transmission of compressive and shear loads, ultimately resulting in injury (Cholewicki \& McGill, 1996; Panjabi, 1992b). 


\subsection{Risk Factors for the Development of Low Back Pain}

There are many activities of daily living that can provoke LBP; among the riskiest activities are MMH tasks: lifting, lowering, pushing, pulling, and carrying loads (Dempsey, 1998). These activities become more dangerous to the human spine when they are performed in awkward postures, carried out repetitively, and/or are performed on heavy objects (da Costa \& Vieira, 2010). Lifters must be concerned with not only what they are handling, but how and where they are performing MMH tasks.

Lifting posture is largely influenced by the start and end location of the load to be lifted, as well as the environment in which the lifting is being performed. When initiating a lift from a low height (e.g. floor), more lumbar flexion is needed to be able to grasp the object, which increases the moment about the $L_{5} / S_{1}$ joint (Hoozemans et al., 2008). It is predicted that for every $10 \mathrm{~cm}$ increase in initial handle height, the moment about the low back reduces by $7 \mathrm{Nm}$, independent of the mass lifted (Hoozemans et al., 2008). Likewise, when working in confined spaces (e.g. underground miners), the low ceiling heights force workers to adopt a more flexed posture (Gallagher \& Unger, 1990). Being in a prolonged flexed posture is of great concern to the worker: $60^{\circ}$ of trunk flexion for more than $5 \%$ of working time puts individuals at an increased risk for LBP (Hoogendoorn et al., 2000). This risk is largely due to creep that can accumulate in the supportive tissues. Creep is the viscoelastic deformation of soft tissues, reducing the passive stiffness of the spine (McGill \& Brown, 1992; Toosizadeh, 2013). Trunk stiffness can decrease up to $39 \%$ after 16 minutes of flexion, with the majority of the stiffness being lost within the first two minutes of flexion exposure (Hendershot et al., 2011). To compensate for a loss in passive stiffness, the active muscular and neural control subsystems must become more active (Panjabi, 1992b); however, they too can become impaired after prolonged trunk flexion. As the ligaments and other soft tissues become stretched, the effectiveness of their mechanoreceptors can become 
impaired, compromising the reflexive responses of the neuromuscular system (Solomonow, 2012).

If there is any damage or fatigue to the supportive tissues, muscles, or neuromuscular system, it will lead to a decreased ability to control movements, which can cause an impaired transmission of compressive and shear loads, ultimately resulting in injury (Cholewicki \& McGill, 1996; Panjabi, 1992b).

Lifting-based MMH jobs are often repetitive in nature. When a lift is performed, the weight being lifted and the muscles that are activated to both stiffen the spine and drive the movement produce forces that act on the spine (Granata \& Marras, 1995; McGill, 1992; van Dieën \& Kingma, 1999). When many lifts are performed in succession, the spine is exposed to cumulative loading, leading to mechanistic changes to the passive tissues of the spine: tissues become stretched and accumulate microdamage (Kumar, 1990), and intervertebral disc height is diminished (Corlett, Eklund, Reilly, \& Troup, 1987). The increased laxity in the spine induced by changes to passive tissues need to be supported by the active musculotendinous and neural control subsystems of the spine (Panjabi, 1992b; Solomonow, 2012). However, this may cause further impairment; as the muscles become more active, they are inadvertently imposing additional forces on the spine (Hodges, van den Hoorn, Dawson, \& Cholewicki, 2009; Marras, Ferguson, Burr, Davis, \& Gupta, 2004). The increase in muscular activity will also lead to eventual fatigue of the supportive musculature (Radwin et al., 2002), leaving the body more susceptible to injury in the event of a perturbation (e.g. slipping; Panjabi, 1992b; Toebes, Hoozemans, Dekker, \& van Dieën, 2014).

Workplace demands differ between occupations. Some workers may need to perform repetitive tasks at a low weight, while others may need to handle very heavy loads infrequently. To ensure that the spine can bear loads, muscles activate to appropriately stiffen the spine to prevent it from buckling (Brown \& McGill, 2010). The back muscles also need to activate with 
the appropriate amount of force to drive the lifting motion (Granata \& Marras, 1995; McGill, 1992; van Dieën \& Kingma, 1999). As the load increases, more force is generated by the muscles, and as a consequence, more force is applied to the spine (McGill, 1992). If the force is large enough, it can lead to instantaneous tissue failure and the development of vertebral endplate fractures (van Dieën et al., 1999). Therefore, it may seem beneficial to decrease the load lifted to protect the spine from peak loads; however, a trade-off exists between spine loads and instability (Cholewicki \& McGill, 1996). When lifting a load of negligible mass, local dynamic stability (LDS) is reduced (less stable) when compared to lifting a load of moderate weight (4-10 kg) (Graham \& Brown, 2012; Graham, Sadler, \& Stevenson, 2012). Subsequently, lifting a light load also reduces one's ability to resist global perturbations (Mavor \& Graham, 2015). When the muscular demand is decreased the spine becomes less stable, which puts the spine at risk for a mistranslation of loads (Cholewicki \& McGill, 1996). Additionally, people tend to lift at a faster rate with lower loads, which may offset any potential benefits (Davis \& Marras, 2000). When increasing the velocity at which lifts are performed, there is a general increase in the mechanical stability of the spine; however, LDS may decrease (Graham \& Brown, 2012). Graham and Brown (2014) revealed that when lifting velocity increases, the lifter's ability to maintain stable spinal muscle activity and stiffness patterns decreases, despite the overall increase in joint stiffness caused by an increase in muscular activity. These results may be driven by the reduced time for biofeedback from the neural control system, limiting the body's ability to correct for an incorrect synchronization of muscular contractions (Graham \& Brown, 2014).

MMH tasks pose a risk to the development of LBP. The introduction of spinal loads and the increase in frequency/magnitude of perturbations put a large amount of strain on the spine. Although additional loads and perturbations are relatively easy for a healthy spine to attenuate, it 
is when $\mathrm{MMH}$ tasks are performed at high loads, in less than ideal environments, done in repetition, and/or in flexed/awkward postures that the tissues are put at a higher risk of being damaged and stretched. To decrease the incidence of LBP, it is imperative that these risky behaviours are properly identified and then minimized in workplace environments.

\subsection{Determining the Risk of Developing Low Back Pain/Injury}

LBP is a very common condition that can be incited by everyday activities and workplace tasks (i.e. MMH). Therefore, to protect workers and to identify potentially risky jobs, ergonomic assessments have been developed. To further identify risky jobs and to provide methods of resolving the associated risk, these activities can be simulated in a laboratory setting to be subjected to more rigorous testing.

\subsubsection{Ergonomic Assessments}

In an attempt to reduce workplace injuries, government guidelines and ergonomic assessment tools have been developed. Since injuries can occur to any part of the body and workplaces can have different task demands, there are many specialized ergonomic assessment tools that exist. As such, the presented tools are for MMH tasks and primarily focus on the back: the National Institute for Occupational Safety and Health (NIOSH) lifting equation, the American Conference of Governmental Industrial Hygienists Lifting Threshold Limit Values (ACGIHLifting TLV), the Manual Handling Assessment Charts (MAC tool), and the Snook Tables.

The NIOSH lifting equation (NLE) was originally developed in 1981 by the American government as an objective tool to evaluate physical demands on lifters in the workplace (Waters, Putz-Anderson, Garg, \& Fine, 1993). Originally, the NLE only evaluated lifters in the sagittal plane, but has since been updated to include asymmetrical lifting tasks with an increased focus on the properties of the load (e.g. handles, mass, and size; Waters et al., 1993). The NLE is designed 
to calculate the recommended weight limit (RWL) that is suitable for safe working conditions up to a typical 8 hour work day (Equation 1) and provides a lifting index (LI) to estimate the level of physical stress on the worker (Waters et al., 1993).

$$
R W L=L C \times H M \times V M \times D M \times A M \times F M \times C M
$$

Ergonomists use the NLE to assess how the lifter interacts with the load at the start and end of the lift. Specifically, the load constant (LC; $23 \mathrm{~kg}$ ) is reduced by a series of multipliers (M), which are determined by measuring the horizontal distance of the hands on the load to the mid-point between the ankles (in $\mathrm{cm} ; \mathrm{H}$ ), the height of the hands (in $\mathrm{cm}$; V), the vertical travel distance of the hands from the start to the end of the lift (in $\mathrm{cm}$; D), the angular location of the load relative to the navel (in degrees; A), the frequency of lifts (lifts/minute and total duration of lifts; F), and how well the load can be grasped (type and presence of handles; C); these multipliers cannot exceed a value of 1.0 (Waters, Baron, \& Kemmlert, 1998; Waters et al., 1993). The actual load that the worker is lifting/lowering is then divided by the RWL to calculate the LI. If the LI is greater than one, it suggests that the worker is at an increased risk for developing lifting-related LBP (Waters et al., 1993). If the LI is greater than three, the worker is at a very high risk of developing a low back injury and design changes to the lifting task are strongly recommended (Waters et al., 1993). More recently, the collaborators of the NLE have updated the equation to be more versatile with job demands in industry, adding the composite lifting index (CLI) and the sequential lifting index (SLI) (Waters, Lu, Piacitelli, Werren, \& Deddens, 2011). The CLI allows for the assessment of multi-task jobs where the task demand may change from lift to lift (e.g. palletizing tasks), while the SLI accounts for those occupations where there are variable task demands (i.e. systematically switching between different lifting tasks over a work day) (Waters et al., 2011). There are, however, limitations to the NLE that reduce its applicability towards all lifting tasks: one-handed 
lifts, lifting while seated/kneeling, lifting unstable objects/living things, restricted space, nonlifting MMH tasks (e.g. carrying, pushing, pulling), working on slippery surfaces, and the use of PPE cannot be evaluated using the NLE.

The ACGIH Lifting TLV was developed by the American Government in 2004. It is a method to establish acceptable weight limits for specific lifting tasks that would protect nearly all workers from developing work-related LBP/shoulder disorders associated with repetitive lifting (Workplace Safety North, 2017). The ACGIH Lifting TLV is largely based on the NLE but is has the advantage of being quicker and more user-friendly while providing similar results (Russell et al., 2007). When using the ACGIH Lifting TLV, ergonomists must determine the lifting duration (i.e. how many hours the worker is lifting for), frequency (lifts/hour), height zone (i.e. the location of the hands at the start and end of lift), and the horizontal distance of the hands on the load to the mid-point between the ankles (Workplace Safety North, 2017). Ergonomists then select the appropriate table based on the frequency and duration of the lifts to score the task (Workplace Safety North, 2017). Using a load constant of $32 \mathrm{~kg}$, a lifting threshold limit value is then calculated based on the tallied score to provide a weight that nearly all workers can repeatedly lift, day after day, without sustaining LBP or injury (Russell et al., 2007; Workplace Safety North, 2017). Being the more convenient version of the NLE, the ACGIH Lifting TLV has similar limitations: not suitable for tasks involving trunk rotation greater than $30^{\circ}$, more than 360 lifts/hour, environments that constrain posture, one-handed lifting, lifting unstable objects/living things, objects with poor handles, unstable footing, and is unable to assess other MMH tasks outside of lifting (e.g. pushing, pulling, carrying) or the use of PPE (Workplace Safety North, 2017).

The MAC tool was developed by the Health and Safety Executive branch of the United Kingdom's government (Health and Safety Executive, 2017). The MAC tool uses a colour scheme 
and numbers to visually aid the ergonomist: green represents a safe behaviour, amber a moderately risky behaviour, red is a more risky and unsafe behaviour, and purple is a very risky behaviour that will likely result in LBP or injury (Health and Safety Executive, 2017). The MAC tool can be used to evaluate MMH tasks that involve lifting, carrying, and team handling operations (Health and Safety Executive, 2017). In lifting situations, the evaluator assesses the load weight/frequency of the lift (i.e horizontal hand distance from the lower back), the vertical lift region (i.e. start and end position of the hands), torso twisting and sideways bending, postural constraints (i.e. immovable objects that the worker must work around), grip on the load, floor surface (e.g. slipperiness, unevenness, slope), and other environmental factors (e.g. temperature, air flow, lighting) (Health and Safety Executive, 2017). These factors are rated individually and summed; a score closer to zero is desired for a very safe task. In load carriage tasks, ergonomists analyze the load weight/frequency, hand distance from the lower back, the asymmetry of the load/torso (i.e. holding the load with one hand vs. two hands symmetrically or asymmetrically), postural constraints, grip on the load, floor surface, environmental factors, carry distance (measured in ranges: green $=2-4 \mathrm{~m}$, amber $=4-10 \mathrm{~m}$, red $=10 \mathrm{~m}$ or more), and whether there are any obstacles the worker needs to overcome while carrying the load (e.g. sloped floor, stairs, closed doorways, climb ladders). Finally, when assessing team handling operations, the ergonomist assesses the load weight (based on number of persons and the weight of the load), hand distance from the lower back, the vertical lift region, torso twisting and sideways bending, postural constraints, grip on the load, the floor surface, environmental factors, and the team's communication, coordination and control (i.e. good, reasonable, poor) (Health and Safety Executive, 2017). The total score of any of the three types of MMH tasks helps the ergonomist prioritize which task needs to be improved to reduce the score as much as possible, and as a result make the task safer for the worker (Health 
and Safety Executive, 2017). The MAC tool does a good job at assessing a variety of MMH tasks but does have its limitations: it is not suitable for pushing/pulling tasks, lifting unstable objects/living things, and does not provide a weight limit to adhere to or consider PPE (Health and Safety Executive, 2017).

The Snook Tables were originally published in 1978 and were revised in 1991, comprising over 25 years of research at the Liberty Mutual Research Centre (Snook \& Ciriello, 1991). The goal of the Snook Tables is to provide the ergonomist with a maximal acceptable weight limit (MAWL) that is safe for a defined percentage of the population (typically $75 \%$ or higher) during lifting/lowering, pushing/pulling, and carrying type MMH tasks (Workplace Safety North, 2017; Snook \& Ciriello, 1991). The experiments used to develop the Snook tables focused on the psychophysical approach: anthropometric, heart rate, and oxygen consumption data were collected and workers were able to adjust the weight/force so they could work all day as hard as possible without straining, being out of breath, or overheated (Snook \& Ciriello, 1991). Ergonomists using the Snook Tables must measure the hand distance from the front of the body, lift/lower distance (i.e distance that the hands travel from the start to the end of the lift/lower), hand height (during a push/pull, or carry), push/pull/carry distance, frequency (i.e number of lifts, lowers, pushes, pulls, or carries performed in a certain amount of seconds, minutes, or hours), and the lift/lower zone (area of the body in which the lift/lower finishes (e.g. floor to knuckle, knuckle to shoulder, or shoulder to overhead); Snook \& Ciriello, 1991). Once the appropriate table has been identified (based on the task, width/hand height, lift/lower distance, lift/lower zone, and frequency), the ergonomist can determine the MAWL based on a given percentage of the population who would be able to perform the work as a daily routine without experiencing an injury (Snook \& Ciriello, 1991). The Snook Tables largely focus on how the worker interacts with the load; however, the 
limitation of this measure is that it does not account for how the environment (e.g. walking over/around obstacles, temperature) or workwear (i.e. PPE) may affect how the worker can perform a task.

The aforementioned ergonomic assessments focus on MMH tasks and primarily evaluate the low back. The NLE is an in depth assessment of how the lifter interacts with the load being handled, whereas the ACGIH Lifting TLV is a quick assessment that provides similar results (Russell et al., 2007). The MAC tool can be applied to more MMH tasks than the NLE and ACGIH Lifting TLV; however, the MAC tool can only help the ergonomist prioritize which tasks need further attention, where both the NLE and ACGIH Lifting TLV provide a recommended weight limit for the worker. Finally, the Snook Tables are able to be applied to a variety of MMH tasks and provide a maximum allowable weight limit based on a percentage of the population, but unlike the MAC tool, they fail to account for environmental conditions that can affect how the worker performs the MMH task. Each ergonomic tool has its strengths and weaknesses, making one more desirable in certain situations than others. There is, however, one limitation that is consistent across each of these tools: none assess the use of PPE. Performing a more specialized biomechanical assessment in a laboratory environment can reveal whether PPE should be included in these ergonomic assessment tools.

\subsubsection{Biomechanical Assessments}

Ergonomic assessments are practical for ergonomists to enter a workplace and evaluate a given task. From their report, they can identify if a job needs to be altered to make it safer for the worker, or if it is adequate as is (Russell et al., 2007). If a more rigorous assessment is needed, or there are concerns about the safety of a task that cannot be evaluated by using an ergonomic tool, a biomechanical assessment can be performed. These assessments are typically done by simulating 
the task in a laboratory and recording kinematic, kinetic, and EMG data. For example, when studying the spine during lifting tasks, researchers may be interested in variables such as the ROM of the trunk (e.g. Bauer et al., 2015), how well an individual can control their trunk during repetitive tasks (e.g. Mavor \& Graham, 2015), the forces and moments applied to the spine (peak and cumulative; e.g. Davis \& Marras, 2000; Norman et al., 1998), and muscle function/coordination (e.g. Graham \& Brown, 2014; Granata \& Marras, 2000). The results from a biomechanical assessment can then be used to provide solutions to task demands or provide insight into injury risk. This ability to gain specific knowledge is why many companies (e.g. Ford Motor Company) have invested in motion capture laboratories, allowing them to evaluate the risks to their workers and to make their products more safe and comfortable for their consumers. Alternatively, companies or groups can approach a research team to investigate unique occupational characteristics such as paramedic lifting techniques/physical demands (e.g. Coffey, MacPhee, Socha, \& Fischer, 2016; Makhoul, Sinden, MacPhee, \& Fischer, 2017), firefighter fitness and injury identification (e.g. Beach, Frost, McGill, \& Callaghan, 2014; Frost, Beach, Crosby, \& McGill, 2015), and police vehicle design/physical exposure (e.g. Donnelly, Callaghan, \& Durkin, 2009; Mc Kinnon, Callaghan, \& Dickerson, 2011), among many others.

Before any conclusions can be made about a task, a data collection session must be performed. Researchers can record a participant's movement behaviour, the forces they produce, and their muscular activity. There are many tools that biomechanists can use to track a person's movement, one example being motion capture. Typically, a motion capture laboratory includes a large open space with many specialized high-speed infrared cameras that line the perimeter. A participant is outfitted with individual reflective markers on specific bony segments and with rigid clusters of markers on the limb's centre of mass (Robertson et al., 2014). The participant is then 
instructed to perform a task (e.g. repetitive lifting), and the reflective markers they are wearing are recorded by the cameras as positional data $(\mathrm{x}, \mathrm{y}, \mathrm{z})$, which is then be processed into meaningful kinematic data. To measure the amount of force a person is exerting on the floor, researchers can use force plates. Force plates allow the researcher to determine the magnitude, direction, and the location of the force. The knowledge of these parameters allows for the calculation of the moment about a given joint, the amount of force (i.e. compression, shear, torsion) applied to a joint, and a participant's centre of pressure, among other analyses (Robertson et al., 2014). To gain insight into muscle function, EMG data can also be collected. EMG sensors collect the voltage in the muscles caused by an action potential propagated by the innervation of a nerve (Robertson et al., 2014). To determine the normalized amount of muscular activation to compare EMG data between participants, maximal voluntary contractions (MVC) are performed to elicit the maximal voltage a muscle can generate (Mathiassen, Winkel, \& Hägg, 1995). The processed EMG data from the movement trials are then normalized to a percentage of MVC (Equation 2).

$$
\left(E M G_{\text {Trial }} \div E M G_{M V C}\right) \times 100=\% M V C
$$

Researchers can decide to collect all of the above parameters in one data collection session or decide on a combination of parameters to adequately answer their research question. After a data collection session is complete, the data are ready to be cleaned and analyzed. Researchers need to ensure the signals obtained are biological (i.e. no sudden, unexpected spikes in signal), have been adequately filtered, and that all marker trajectories are real/correct (e.g. no large unexpected translations of marker trajectories) (Robertson et al., 2014). Once the data are deemed appropriate, they can then be imported into a musculoskeletal model (e.g. Visual 3D, OpenSim). These models are scaled from the individual markers that were placed on bony landmarks, and the motion of individual limbs are tracked using marker clusters (Robertson et al., 2014). The software 
can then calculate the desired variables (e.g. joint angles, joint moments, joint forces) using 3D kinematics/kinetics. Very simply, these calculations are done through linear transformations and aligning of local coordinate systems (LCSs) to each other (e.g. the LCS of the shank to the LCS of the thigh for knee angle calculations), or to/from the global coordinate system (GCS) (e.g. forces/torque applied to the foot LCS is transformed to the GCS before the force/torque can be applied to the shank; Robertson et al., 2014). Depending on the model, EMG can be used to: estimate muscle activations using EMG-informed computed muscle control (e.g. Demircan, Khatib, Wheeler, \& Delp, 2009), prescribe the muscle forces (as a percentage of MVC; e.g. McGill, 1992), be used to assist forward-inverse dynamics modelling (e.g. Shourijeh, Smale, Potvin, \& Benoit, 2016), or be interpreted on its own with advanced mathematical concepts (e.g. wavelet coherence; Hay, Wachowiak, \& Graham, 2016).

Once the raw data from the data collection session have been cleaned (i.e. removal of unexpected spikes and marker trajectories are labelled properly) and processed through a musculoskeletal model (i.e. to obtain an output such as joint angles), researchers can interpret the model's output variables (e.g. joint kinematics, joint moments/forces, muscle activation). These variables can be evaluated individually to obtain specific insight into task demands, or together to explain the overall change to a system. Joint kinematics are used to describe the motion of a joint in three planes (sagittal, frontal, and transverse). Researchers can choose to report variables such as maximum, minimum, mean joint angles, ROM, as well as angular/linear velocity and acceleration, among many others, to describe changes in motion throughout or between tasks. Moments about and forces applied to joints can be used to explain the amount of stress placed on supportive tissues (Coenen, Kingma, Boot, Bongers, \& van Dieën, 2014). Moments can be reported as the maximum observed value during a movement or the average value that occurred 
throughout the task. Joint forces (e.g. spinal loads) incorporate the total force acting in a joint in all three directions (i.e. compression, shear, axial torsion), and are often reported as peak or cumulative loads (Callaghan, Salewytsch, \& Andrews, 2001). Cumulative loads are the integrated time histories of net spinal loads during a given task, providing insight into tissue stress over time, whereas peak loads provide a maximal value over the course of the whole trial (Callaghan, Howarth, \& Beach, 2011). Muscle activation profiles can be used to determine the coordination and magnitude of muscle contractions (e.g. van Dieën et al., 2003). This can be useful for identifying physiological changes such as fatigue (e.g. Cifrek, Medved, Tonković, \& Ostojić, 2009) or to explain bracing strategies such as co-contraction (e.g. Granata \& Marras, 2000). When concerned about the performance of the spine, it is appropriate to employ the dynamic systems approach: the study of how parts of a system act not only individually, but together to affect the overall behaviour of the system (Reeves \& Cholewicki, 2013). Since the spine is made up of three subsystems, it is important to uncover how these subsystems work together to achieve the overall goal of controlling spine movements.

One method to assess how well a system is performing is to calculate its LDS. By reconstructing kinematic data from the time domain into a state space, local divergence exponents (i.e. maximum finite-time Lyapunov exponents $\left(\lambda_{\max }\right)$ ) are used to describe whether local kinematic errors grow over time or if they are similar to a mean trajectory. This is done by comparing infinitesimally close trajectories within the state space by calculating the exponential rate of divergence of these neighbouring trajectories (Bruijn et al., 2010; Graham et al., 2012; Granata and Gottipati, 2008; Mavor and Graham, 2015; Rosenstein et al., 1993). This allows for the quantification of how a system (i.e. the spine) reacts following a perturbation (i.e. from muscular contractions, control errors, or movement of load). There is a negative relationship 
between $\lambda_{\max }$ and system performance, where a small $\lambda_{\max }$ represents a better-performing system (i.e. the individual continued on their mean trajectory over time) and a large $\lambda_{\max }$ represents a system that performed poorly (i.e. following a perturbation the behaviours of the system changed and no longer follow the mean trajectory) (Reeves \& Cholewicki, 2013).

Simulating a workplace task in a laboratory to collect motion capture, force plate, and EMG data allows researchers to identify how specific task demands affect joint kinematics, moments about and forces applied to joints, and the muscular contribution to movement. These variables can provide more in-depth insight than ergonomic assessments and can build on their limitations. More specifically, biomechanical analyses are capable of addressing how protective footwear alters how humans perform MMH tasks whereas ergonomic assessments cannot.

\subsection{Protective Footwear}

Many occupations that require employees to frequently lift objects take place in hazardous environments. Thus, PPE have been designed to protect workers from these hazards. One of the more frequently prescribed types of PPE is work boots. In Canada, CSA Grade 1 work boots are the only accepted form of work boot in heavy industrial work environments (e.g. construction, mining, forestry; Canadian Centre for Occupational Health and Safety). CSA Grade 1 work boots have a steel/composite toe cap to prevent the toes from being crushed and a steel shanked insole to prevent punctures to the bottom of the foot (Canadian Centre for Occupational Health and Safety). It is further recommended that if there is a potential for ankle cuts or abrasions that workers wear boots that are $13 \mathrm{~cm}$ high (from the top of the sole to the top of the upper) and if the occupation involves walking over uneven surfaces, work boots should have a height of $20 \mathrm{~cm}$ and be of lace-up style (WorkSafeBC). This specific boot height legislation is in place to protect against 
ankle injuries (e.g. abrasions, sprains) by providing additional support and material protection to the ankle (Canadian Centre for Occupational Health and Safety).

Several industries (e.g. mining, construction) require their employees to wear protective footwear with metatarsal guards. A metatarsal guard is a metal sheath that covers the dorsal aspect of the metatarsal area; designed to provide additional protection from foot-crushing injuries and, in the case of metal work, protect the foot against hot embers (WorkSafeBC). Although metatarsal guards provide an additional safety barrier between the environment and the foot, the extra steel makes the boot heavier and stiffer which has the potential to affect ankle ROM (e.g. Böhm \& Hösl, 2010; Cikajlo \& Matjacić, 2007) and lifting mechanics.

In workplace environments where uneven surfaces are not a concern (e.g. warehouses), employees can wear CSA Grade 1 steel-toed work shoes (WorkSafeBC). Work shoes have the same requirements as their work boot counterparts (i.e. steel shanked sole, steel-toe cap); however, there is no material encompassing the ankle, possibly preserving the ROM of the ankle.

Protective footwear provides adequate protection to the foot from falling objects and punctures; however, they have been shown to affect human movement (Böhm \& Hösl, 2010; Cikajlo \& Matjacić, 2007). Boot stiffness and weight are two important components of the work boot that can alter how the wearer performs movement tasks. Cikajlo and Matjacić (2007) found that boot stiffness negatively influenced the kinematics and kinetics of the ankle during gait, decreasing ankle ROM, moment, and power; however, no significant changes occurred at the hip and knee. Boot stiffness also affects muscular activation profiles during the gait cycle. Research by Böhm and Hösl (2010) showed that boot stiffness increased co-contraction at the level of the knee (i.e. vastus lateralis and semitendinosus), raising concerns that boot stiffness can decrease the efficiency of the gait cycle - leading to early fatigue in the muscles at the knee. The mass of the 
work boot also has implications to gait mechanics. Chiou and colleagues (2012) assessed how stepping over obstacles was affected by four types of firefighter boots. Boot weight had a negative relationship with toe clearance height and caused the participants to swing their feet more outwards (i.e. more hip abduction) to clear the obstacle successfully (Chiou et al., 2012). Boot weight and stiffness are of concern to the mechanics of the human body; as companies try to provide more protection to the foot, they may be inadvertently affecting how people can traverse potentially dangerous terrain as well as carry out other workplace tasks.

Given that human gait is altered while wearing work boots, it is possible that similar changes may occur during lifting-based tasks. Currently, there is limited research on how work boots affect lifting mechanics. To the best of the author's knowledge, only one such research project has been performed. Blench (1998) assessed the effects of work boots on two-dimensional lower limb and trunk kinematics as well as muscle activity during a lifting task. Blench (1998) found that work boots decreased ankle ROM and trunk inclination angle (i.e. trunk was more parallel with the floor). Time-normalized EMG indicated that multifidus and biceps femoris were recruited more while wearing work boots when grasping the load from the floor (Blench, 1998).

Although not with work boots, Beach and colleagues (2014) experimentally immobilized the right ankle of participants using an ankle brace and asked them to perform a series of lifting tasks. Reduced ankle ROM caused participants to increase their lumbar spine sagittal motion, which resulted in greater $\mathrm{L}_{4} / \mathrm{L}_{5}$ anteroposterior shear forces (Beach, Frost, Clark, et al., 2014). Although only unilateral ankle immobilization was assessed by Beach et al. (2014), their results may help explain the observed changes in lifting kinematics when wearing work boots (Blench, 1998). Restricting the ROM of the ankle disrupts the kinematic chain, altering how healthy individuals perform movement tasks (Beach, Frost, Clark, et al., 2014). Therefore, it is important 
to fully understand how restricted ankle mobility (via protective footwear) independently affects low back injury risk during lifting tasks. Results from this investigation can be used to establish appropriate work boot guidelines and design that preserves ankle and trunk kinematics while ensuring the safety of the worker.

\section{$\underline{\text { 2.6 Summary }}$}

LBP affects a large portion of our population. Although LBP is multifactorial, MMH-based tasks are regarded as one of the largest risk factors for its development (da Costa \& Vieira, 2010). When MMH tasks are performed in the workplace, there are many additional variables that may be present that can make the task more dangerous (e.g. awkward postures, repetition, the environment, weight of objects). Ergonomic assessment methods have been developed to identify risky tasks; however, all of them do not include protective footwear as a variable when evaluating MMH tasks and LBP. Boot stiffness has been shown to decrease ankle ROM during gait (Böhm \& Hösl, 2010; Cikajlo \& Matjacić, 2007), and reduced ankle mobility during lifting has been shown to negatively impact trunk kinematics (Beach, Frost, Clark, et al., 2014). However, the effects of work boots on trunk kinematics has received little attention in the literature: our understanding is limited to $2 \mathrm{D}$ analyses (Blench, 1998) and there have been no investigations on metatarsal guards. Results could provide insight into whether protective footwear should be included as a variable when evaluating LBP concerns in a workplace setting and provide insight for future designs of protective footwear.

Thus, as mentioned in the introduction, the purpose of this thesis was to assess the effects of steel-toed shoes (unlaced), steel-toed boots (work boot), and steel-toed boots with a metatarsal guard (MET) on lifting mechanics (i.e. 3D kinematics of the lower limbs and trunk, low back sagittal net reaction moments, and LDS of the lower limbs, lower back and upper back) on both male and female participants. It was hypothesized that ankle plantar/dorsiflexion ROM would be 
reduced in the work boot and MET conditions, where the MET condition would be the most restrictive. The expected reduction in ankle ROM was hypothesized to increase the lumbar flexion angle (Beach, Frost, Clark, et al., 2014), which would lead to larger sagittal net reaction moments about the low back (Hoozemans et al., 2008). These predicted changes to trunk kinematics were hypothesized to negatively impact LDS at each segment going up the kinematic chain; the greatest change was hypothesized to occur in the lower and upper back segments. It was also hypothesized that males and females would react similarly to the different types of protective footwear.

\section{CHAPTER 3: METHODS}

\section{$\underline{3.1 \text { Participants }}$}

Twelve male and 12 female participants were recruited from the general university population via posters and word of mouth. Participants' mean age, height and weight were 21.7 years $(\mathrm{SD}=3.1), 171 \mathrm{~cm}(\mathrm{SD}=7.1)$, and $71.4 \mathrm{~kg}(\mathrm{SD}=10.8)$, respectively; detailed demographics can be found in Table 1. Specific exclusion criteria included not being able to fit into the provided footwear, cardiovascular conditions, neurologic disorders (neuropathy, neurodegenerative conditions), low back pain (discogenic, mechanical, myofascial), use of medication (antiinflammatories, analgesics, anticonvulsants, antidepressants), history of low back injury (discogenic, mechanical), history of ankle injuries (sprains, breaks), use of anticoagulant therapy, stroke or a transient ischemic attack, spine trauma, motor vehicle accident, lumbar spine surgery, hypertension, connective tissue disease, and focal neurological symptoms (sensory/motor). These exclusion criteria were selected based on the physiological response to exercise, to minimize possible responses due to kinesiophobia (e.g. Ross, Mavor, Brown, \& Graham, 2015), to make sure that the participant could complete the protocol, and to limit any responses due to a limited ROM in the ankle/back. Participants who had previous ankle injuries $(n=2)$ were evaluated using 
the lunge test (as described by Bennell et al. (1998)), which assesses bilateral asymmetries in the ankle by testing its functional ROM. Both participants who were tested displayed similar ankle ROM on both sides, and, therefore, were included in this study.

Table 1. Participant Demographics.

\begin{tabular}{ccccc}
\hline & $\begin{array}{c}\text { Height }(\mathrm{cm}) \\
\text { Mean }(\mathrm{SD})\end{array}$ & $\begin{array}{c}\text { Weight }(\mathrm{kg}) \\
\text { Mean }(\mathrm{SD})\end{array}$ & $\begin{array}{c}\text { Age (years) } \\
\text { Mean (SD) }\end{array}$ & $\begin{array}{c}\text { Weight lifted (kg) } \\
\text { Mean (SD) }\end{array}$ \\
\hline Male & $175.3(6.30)$ & $77.10(7.39)$ & $22.00(3.67)$ & $9.48(2.87)$ \\
Female & $165.9(4.16)$ & $65.61(10.8)$ & $21.42(2.43)$ & $5.35(1.21)$ \\
All & $170.6(7.09)$ & $71.36(10.8)$ & $21.71(3.06)$ & $7.41(3.02)$ \\
\hline
\end{tabular}

All participants were recruited from the general university population and had all met the inclusion criteria outlined in the participant information letter (Appendix A). SD = standard deviation.

\subsubsection{Consent}

Before the data collection session began, participants were first fitted to a pair of work boots to ensure their eligibility. Once fitted, the boots were removed, and participants read and signed the participant information letter (Ethics \#H11-16-06), which clearly described the experimental task and technology used (Appendix A).

\section{$\underline{3.2 \text { Procedure }}$}

\subsubsection{Footwear}

Each participant wore a single pair of CSA Grade 1 work boots with a 6-inch upper (Aggressor, Lynx II 6", Mark's Work Warehouse Ltd., Canada; male and female models) that were provided by the research team. The work boot used is a general-purpose work boot marketed for construction and trades. This particular model was selected based on feasibility and that a male and female version existed, allowing a fair comparison between sexes. To accommodate differences in foot size, participants were able to choose from male sizes 9 to 12 and female sizes 7 to 9 (total boots $=7$ ). To emulate steel-toed shoes (unlaced condition), the provided work boots were unlaced to just below the level of the ankle and the tongue of the boot was pulled forward (Figure 1A). For the work boot condition, the provided steel-toed boots were laced up all the way 
to the top of the upper (Figure 1B). For the MET condition, a removable metatarsal guard made from hardened plastic (MetGuard, Impacto Protective Products Inc., Canada) was attached to the dorsum of the fully laced work boot (Figure 1C). The same boot was used for all three conditions to control for differences in sole design and heel drop that may be present between different models of boots. The work boots were tied by the same researcher for all conditions using a standard bow knot. The researcher ensured similar tightness between left and right sides and that it was not causing discomfort to the participant.

The three footwear conditions were block-randomized so that an equal number of participants performed the lifting protocol in each of the 6 possible orders (e.g. four participants completed the study in the order of unlaced, laced, then MET; four participants had the order of laced, MET, unlaced etc.).

To track the foot, reflective markers were placed on the boot at the location of the participant's first and fifth metatarsals, calcaneus, and lateral malleoli using double sided tape (Appendix B, Figure B1). Marker positions remained unchanged between conditions.

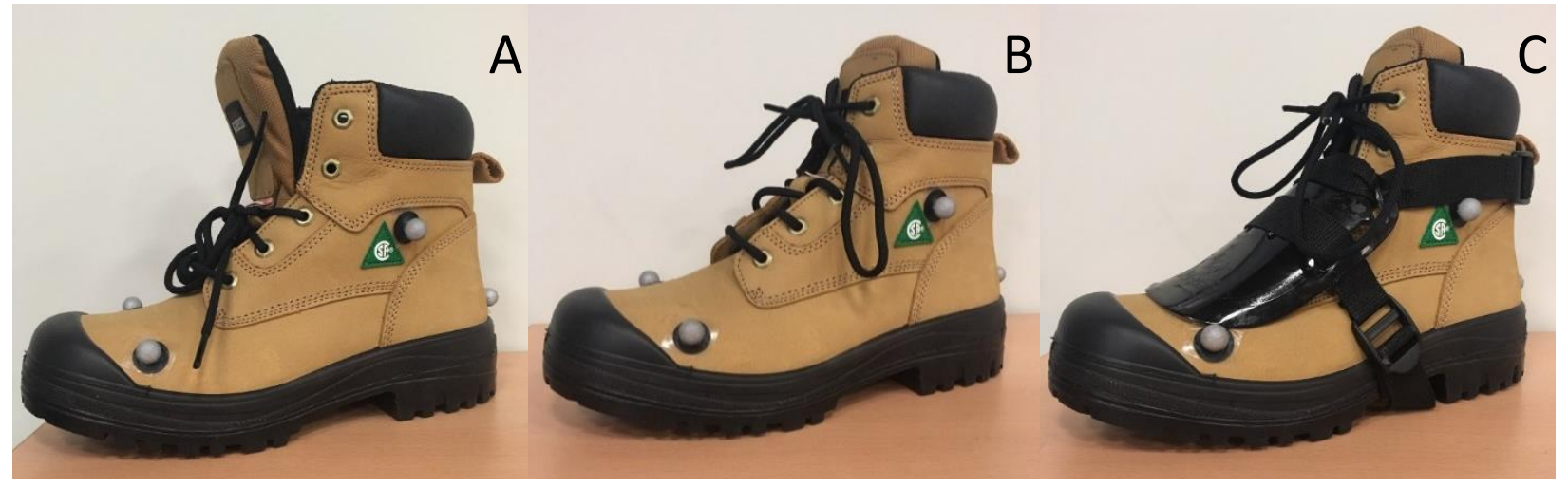

Figure 1. Protective Footwear Conditions. Footwear conditions were block randomized to the three protective footwear types: A) unlaced, B) work boot, C) MET.

\subsubsection{Determining Maximum Back Strength}

Once informed consent was given, participants were asked to pull against a uniaxial load cell (60001A500-1000, Sensortronics, NZ) to determine their maximum back strength (Mehta, 
Lavender, \& Jagacinski, 2014). The load cell was adjusted to be the same height as the handles of the box used during the lifting protocol (Figure 2; Mehta et al., 2014). The load cell was connected to a power source (XP power, VCS70US24, USA) and an amplifier (VOCM-491-2, Intertechnology, USA), which was connected to an analogue-to-digital board (NI USB-6363, National Instruments, USA). The voltage data outputted by the load cell were then read by the computer at $100 \mathrm{~Hz}$ and converted to kilograms using custom LabVIEW software (LabVIEW 2013, National Instruments, USA), which was developed using the factory calibration documents. Ten and $20 \%$ of the maximum amount of force (Newtons) that the participant was able to apply to the load cell was converted to kilograms and used to weigh down the box during the lifting trials.

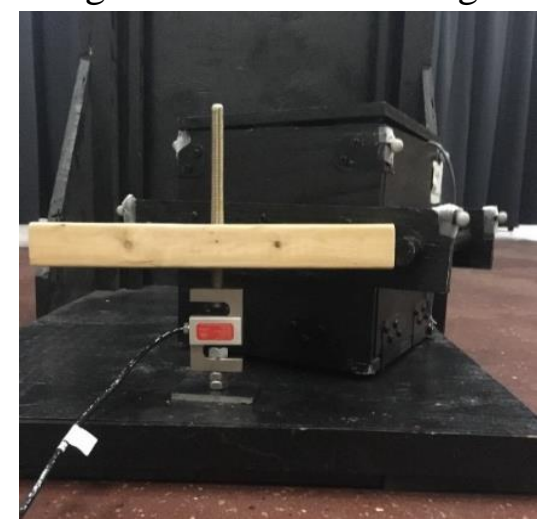

Figure 2. Setup for Determining Maximum Back Strength. Participants were asked to pull straight up on the handle using only their back. Participants were instructed to keep their legs straight and to not use any force from their feet. The handle was adjusted to be the same height as the box's handles (Mehta et al., 2014).

\subsubsection{Participant Preparation and Equipment}

Following the back strength testing, participants were asked to change into a custom-made spandex motion capture suit. After the participant changed, anthropometric measurements were completed (height and weight) using a physician scale (Detecto 339, Detecto, USA).

Participants were then outfitted with wireless electromyography (EMG) sensors (Trigno, Delsys, USA) collecting at $2040 \mathrm{~Hz}$ for seven muscles bilaterally: multifidus, lumbar erector spinae, thoracic erector spinae, latissimus dorsi, internal oblique, external oblique, and rectus 
abdominis as per Cholewicki and McGill (1996). Once all EMG were placed on the appropriate muscle sites, the participant conducted three separate maximum voluntary contraction trials (MVC): resisted sit-ups (flexion, rotation, lateral bending), resisted back extensions (extension, rotation), and resisted latissimus pull-downs (with the elbow and shoulder flexed at $90^{\circ}$, the arm was adducted $0^{\circ}$ (frontal plane), $45^{\circ}$, and $90^{\circ}$ (sagittal plane)). Although EMG data were collected for all movement trials, the data are not reported within this thesis.

Participants then put on their work boots, which were laced by the researcher (according to the footwear condition). Once the participant was outfitted with their boots, individual passive reflective markers (12.7 mm, B \& L Engineering, USA) were placed on specific anatomical landmarks, and rigid marker clusters were placed on the lateral sides of the limbs about the centre of mass, on the centre of the sacrum, and over the $\mathrm{T}_{10}-\mathrm{T}_{12}$ vertebrea (Appendix $\mathrm{C}$ ).

For all motion trials, whole-body kinematics were collected using a 10-camera motion capture system (Vantage V5, Vicon, UK) at $120 \mathrm{~Hz}$. Ground reaction force (GRF) data were collected at $2040 \mathrm{~Hz}$ by two force plates (FP-4060, Bertec, USA) positioned in parallel, directly beside each other. The anologue data from the force plates were collected and syncronized with the kinematic data through a 64-channel analogue-to-digital converter (Lock+, Vicon, UK). The digital data from the EMG sensors were syncronized with the kinematic data through the Delsys Trigger module (A-Tech Instruments Ltd., SP-U02, Canada).

After all the markers were placed on the participant, they were asked to stand quietly in the standard Vicon participant calibration position (i.e. motorbike pose: standing straight up with their shoulders abducted $90^{\circ}$, elbows flexed $90^{\circ}$, and their hands pronated) with each foot on a separate force plate for two, five-second static trials. These trials were used as a reference to scale the biomechanical model used to calculate the kinematic and kinetic variables (i.e. joint angles, linear 
and angular velocities, moments; Visual 3D V5, C-motion, USA). To train the labeling algorithm in the motion capture software (Nexus 2.5, Vicon, UK), participants were taken through the full ROM in all planes of their major joints: ankles, knees, hips, lumbar spine, shoulders, elbows, wrists, and neck.

\subsubsection{Lifting Protocol}

Participants performed two repetitive lifting protocols (protocol A and protocol B) from floor to waist height under three randomly assigned footwear conditions ( 3 footwear $\mathrm{x} 1$ load $=3$ movement trials; block randomized) - all movement trials were performed on the two force plates. A custom-made shelving unit was used to adjust the lifting height for each participant; when the box was placed on the top platform the handles were in line with their anterior superior illiac spines, this was done to ensure that each participant lifted with a similar range of motion based on their height.

For protocol A, participants lifted a hollow box $(25 \mathrm{~cm}$ x $25 \mathrm{~cm}$ x $25 \mathrm{~cm}$ with handles that are $2.5 \mathrm{~cm}$ in diameter) that was weighted to match $10 \%$ of their maximum back strength; males lifted an average of $9.48 \mathrm{~kg}(\mathrm{SD}=2.9)$ and females lifted an average of $5.35 \mathrm{~kg}(\mathrm{SD}=1.2)$. Participants performed 30 repetitive lifts at $10 \%$ of their maximum back strength to the beat of a metronome (6 lift cycles/minute; 10 seconds/cycle; 24 beats/minute). The lifting pace of 6 cycles/min was selected to simulate a low risk lifting pace in industry (Fathallah, Marras, \& Parnianpour, 1998) and to be comparable to previous research (Mavor \& Graham, 2015). Thirty lift cycles were chosen to ensure that there were enough continuous lifting cycles to perform LDS analyses (Graham, 2012). The weight of $10 \%$ of maximum strength was selected to challenge the participants' control systems while not being overly challenging so they were able to complete the protocol (e.g. Sadler, Graham, \& Stevenson, 2013). One full lift cycle consisted of the following: beginning in an unloaded upright stance, participants lifted the box from waist height and placed 
it on the floor $(2.5 \mathrm{~s})$, released the box, and returned to an unloaded upright posture $(2.5 \mathrm{~s})$. When prompted, participants grabbed the box from the floor and placed it on the shelf at waist height $(2.5 \mathrm{~s})$ and again, released the box and returned to an upright unloaded stance $(2.5 \mathrm{~s})$. Participants were given $\sim 5$ minutes of rest between each trial to recover from any fatigue, and to allow for the setup of the next movement trial. Participants were asked if they felt comfortable to continue before each subsequent trial. The lifting protocol is depicted in Figure 3. All participants were told that they could lift using any style they wished but were instructed to be as consistent as possible between conditions. Participants were given a familiarization session (2-5 minutes) with an identical box made of Styrofoam to practice the timing of the metronome. Once both the researcher and participant felt comfortable that they could consistently follow the metronome, the participant was given the weighted box to practice 1-3 lifting cycles. Once confident with the timing, the participant's foot positions were outlined so they could maintain a similar stance for each condition. A failed trial was defined as one where the researcher felt that the participant was not adequately following the beat of the metronome. These participants were familiarized again before continuing.

For protocol B, participants lifted the same box as described in protocol A; however, the box was weighed down to match $20 \%$ of the participant's maxumum back strength; males lifted an average of $18.90 \mathrm{~kg}(\mathrm{SD}=5.8)$ and females lifted an average of $10.63 \mathrm{~kg}(\mathrm{SD}=2.4)$. Participants were instructed to perform 5 repetitive lift cycles at their preferred lifting speed. This protocol was chosen so that participants could move in an unconstrained manner (i.e. their own lifting speed). The weight of $20 \%$ of their back strength was chosen to make this task more challenging, while limiting the amount of lifts that were performed, to elicit more pronounced changes that may occur due to footwear. One full lift cycle consisted of the following: beginning in an unloaded upright 
stance, participants lifted the box from waist height and placed it on the floor, released the box, and returned to an unloaded upright posture. Participants grabbed the box from the floor and placed it on the shelf at waist height and again, released the box and returned to an upright unloaded stance. Participants were given $\sim 5$ minutes of rest between each trial to recover from any fatigue, and to allow for the setup of the next movement trial. Participants were asked if they felt comfortable to continue before each subsequent trial. Participants were allowed to move their foot position from protocol $\mathrm{A}$; however, this new position was outlined to maintain a similar stance between conditions. Data from protocol B are not reported within this thesis.

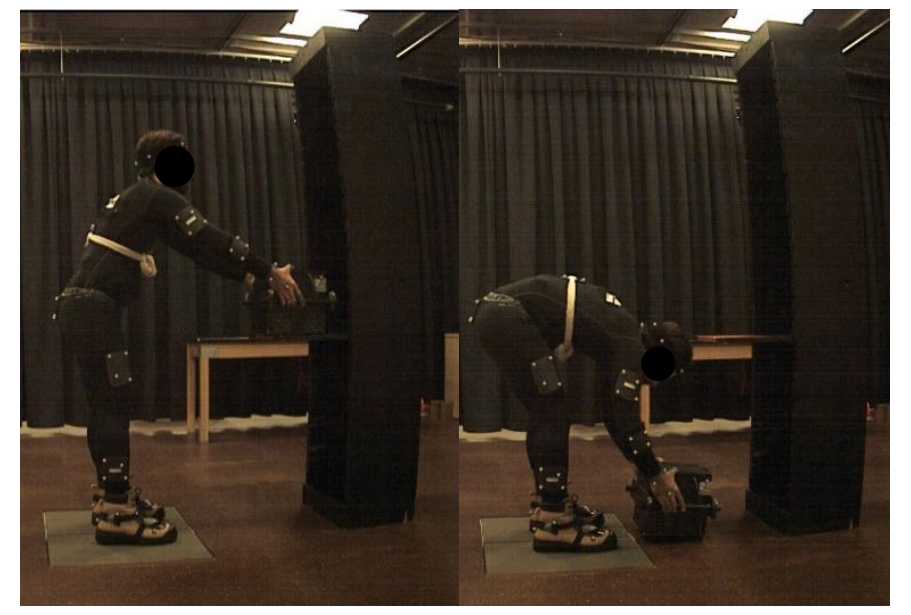

Figure 3. Visual Representation of the Lifting Task. Participants performed 30 freestyle lifts to the beat of a metronome at $10 \%$ of their maximum back strength. The top platform was adjusted so that the box handles were at waist height. Image distortion is caused by the camera lens.

\subsection{Data Analysis}

Visual 3D was used to develop a full-body biomechanical model (e.g. Ross, Mavor, Brown, \& Graham, 2015; Figure 4) with 6 degrees of freedom joints at the ankle, knee, hip, low back, shoulders, and wrists. The generic model was scaled for each participant based on their calibration trial. This model was used to calculate 3D joint angles of the lower limbs, low back (defined as the angle between the marker cluster placed on the sacrum and $\mathrm{T}_{10}-\mathrm{T}_{12}$ vertebrae) and the upper back (defined as the angle between the cluster placed on the $\mathrm{T}_{10}-\mathrm{T}_{12}$ vertebrae and the $\mathrm{C} 7$ and scapula markers); linear and angular velocities of the lower limb segments (i.e. feet, shanks, and 
thighs), pelvis, lower back, and upper back (positions and orientations are relative to the global coordinate system); and the net reaction moments about the low back. All subsequent calculations were performed using custom Matlab software (R2015b, The MathWorks Inc., USA).

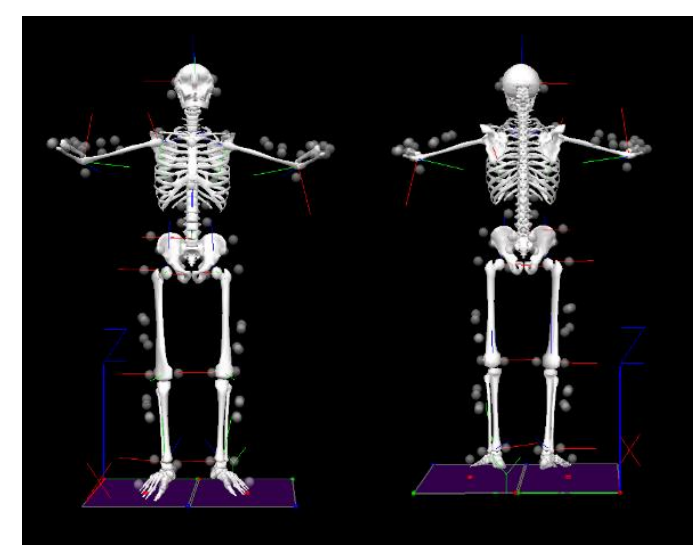

Figure 4. Biomechanical Model from Visual 3D. This model was used for all calculations.

\section{$\underline{\text { 3.3.1 Kinematics }}$}

Each participant's joint angle (ankle, knee, hip, low back) and velocity data (low back) were first filtered using a second-order low pass Butterworth filter with a cut-off frequency of 6 Hz. These data were then divided into individual lift cycles (box on the shelf to the next instance of box on the shelf) and normalized to 101 data points using a cubic spline interpolation (0-100\% of lift cycle). Mean joint angles from the static calibration trial were subtracted from the trial data to normalize joint angles to $0^{\circ}$ in quiet standing. Data from each lift were then ensemble averaged to represent the mean trajectory for the entire lifting condition. The maximum and minimum angles and velocities of the mean trajectory were then found using the maximum function in Matlab. Finally, the minimum observed angle was subtracted from the maximum angle to represent the ROM of each joint.

\subsubsection{Kinetics}

GRF data were filtered using a second-order zero-lag low pass Butterworth filter with a cut-off frequency of $10 \mathrm{~Hz}$ prior to moment calculations. Following the low back sagittal net 
reaction moment calculations, the data were filtered using a second-order low pass Butterworth filter with a cut-off frequency of $6 \mathrm{~Hz}$. These data were divided into individual lifts and normalized to 101 data samples (0-100\% of lift cycle). Data from each lift were then ensemble averaged to represent a mean trajectory over the entire lifting condition from which the maximum and minimum observed net reaction moments were found. To make fair comparisons on sex differences, net reaction moments were normalized as a percentage of body weight (i.e. (moment / body weight) x $100=$ normalized moment).

\subsubsection{Local Dynamic Stability}

Linear and angular velocity data of each segment tested were first filtered using a secondorder low pass Butterworth filter with a cut-off frequency of $6 \mathrm{~Hz}$. Then, using the method of delays, the process in which the time series data are delayed to produce more dimensions (Rosenstein, Collins, \& De Luca, 1994), the continuous data over the whole trials from each body segment were reconstructed into a 12-dimensional state space using the segment's linear $(\dot{x}, \dot{y}, \dot{z})$ and angular $(\dot{\theta}, \dot{\varphi}, \dot{\psi})$ velocities and their time lag (L) counterparts (Equation 3). Velocities were used to reduce non-stationarities in the data.

$$
y=\left[\begin{array}{cccccccccccc}
\dot{x}_{1} & \dot{y}_{1} & \dot{z}_{1} & \dot{\theta}_{1} & \dot{\varphi}_{1} & \dot{\Psi}_{1} & \dot{x}_{L 1} & \dot{y}_{L 1} & \dot{z}_{L 1} & \dot{\theta}_{L 1} & \dot{\varphi}_{L 1} & \dot{\Psi}_{L 1} \\
\dot{x}_{2} & \dot{y}_{2} & \dot{z}_{2} & \dot{\theta}_{2} & \dot{\varphi}_{2} & \dot{\psi}_{2} & \dot{x}_{L 2} & \dot{y}_{L 2} & \dot{z}_{L 2} & \dot{\theta}_{L 2} & \dot{\varphi}_{L 2} & \dot{\psi}_{L 2} \\
\ldots & \ldots & \ldots & \ldots & \ldots & \ldots & \ldots & \ldots & \ldots & \ldots & \ldots & \ldots \\
\dot{x}_{n} & \dot{y}_{n} & \dot{z}_{n} & \dot{\theta}_{n} & \dot{\varphi}_{n} & \dot{\psi}_{n} & \dot{x}_{L n} & \dot{y}_{L n} & \dot{z}_{L n} & \dot{\theta}_{L n} & \dot{\varphi}_{L n} & \dot{\psi}_{L n}
\end{array}\right]
$$

A leading time lag of $10 \%$ of the average lifting cycle was selected based off previous work and to ensure that all trials were analyzed similarly (e.g. Bruijn, van Dieën, Meijer, \& Beek, 2009; Graham, 2012; Granata \& England, 2006). A 10\% time lag is optimal for reconstructing data for LDS estimations by limiting the amount of redundancy and irrelevance in the data set, and is similar to the lags obtained using other methods such as the first minimum from the average mutual information function (Graham, 2012; Granata \& England, 2006; Rosenstein et al., 1993). The state 
spaces were then time normalized, using a cubic spline interpolation, so that the entire sample length was a factor of the sample frequency, number of lifting cycles performed, and the time it took to complete one lift cycle (i.e. $120 \mathrm{~Hz} * 30$ cycles $* 10$ seconds $=36000$ data points). Time normalizing the state space ensures that $\lambda_{\max }$ calculations are not biased by time series length and that all conditions have a similar number of data points (Bruijn et al., 2009; Rosenstein et al., 1993). The magnitude of the state spaces were also normalized to give equal weight to both the angular and linear velocity data. This was done by dividing the angular velocity, linear velocity, and their time lag counterparts by the sum of their respective standard deviations (Dupeyron, Rispens, Demattei, \& van Dieën, 2013). $\lambda_{\max }$ was then estimated by a linear line-of-best-fit to a section of the divergence curve calculated as (Equation 4):

$$
y(i)=\frac{1}{\Delta t}\left[\ln d_{j}(i)\right]
$$

where $\left[\ln d_{j}(i)\right]$ represents the average logarithm of divergence, $d_{j}(i)$, for all pairs of nearest neighbours, $j$, throughout a certain number of time steps $(i \Delta t)$. The slope was calculated from 0 to 0.5 lifts (Graham \& Brown, 2012; Mavor \& Graham, 2015).

\subsection{Statistical Analysis}

All statistical analyses were performed using SPSS 23 (IBM Corporation, USA) with an alpha cut off of $\alpha=0.01$ to control for type II errors. Trends were identified as variables with a pvalue of $>0.01$ and $<0.05$. For all tests, effect sizes were interpreted as small $( \pm 0.1)$, medium $( \pm$ $0.3)$, and large $( \pm 0.5)$ and power were interpreted as sufficient to detect a difference at $\beta=0.8$ (Field, 2013).

\subsubsection{Kinematics \& Kinetics}

Dependent t-tests with a within-subject factor of side, were run on the kinematic data to determine if there were differences between left and right sides of the body; data were first 
corrected to ensure proper alignment up of coordinate systems. For those variables whose data violated parametric assumptions, Wilcoxon Signed Ranked tests were used.

After determining that there were no significant differences between sides, kinematic data from the left and right sides of the body were averaged together.1x3 mixed-design repeatedmeasures ANOVAs, with a between-subject factor of sex and a within-subject factor of protective footwear type, were used to evaluate if there were any changes to whole-body kinematics and low back kinetics caused by the type of protective footwear. Since changes in the test variables were small, least significant difference (LSD; i.e. no correction was made based on the amount of tests performed) post-hoc analyses were used to find the location of statistically significant results, while controlling for type II errors (by decreasing alpha to 0.01).

Variables that violated parametric assumptions were evaluated using Friedman's rank tests; variables that reached statistical significance were post-hoc analyzed using Wilcoxon Signed Ranked tests to determine the location of the difference.

\subsubsection{Local Dynamic Stability}

First, dependent t-tests with a within-subject factor of side were used to determine if there were any differences in $\lambda_{\max }$ values between left and right sides of the body. Once it was determined that there were no differences between sides, the data were averaged together.

Lower and upper back results were analyzed on their own using $1 \times 3$ mixed-design repeated-measures ANOVAs, with a between-subject factor of sex and a within-subject factor of protective footwear type.

Additionally, to analyze the effect of protective footwear on $\lambda_{\max }$ values going up the kinematic chain (i.e. foot, shank, thigh, low back, upper back), a $6 \times 3$ mixed-design repeated- 
measures ANOVA was used, with a between-subject factor of sex and two within-subject factors of protective footwear type and segment.

\section{CHAPTER 4: RESULTS}

\subsection{Kinematics \& Kinetics}

There was a main effect of footwear type on ankle dorsiflexion angle $(\mathrm{F}=5.411, p=0.008$, $\eta^{2}=0.197$; Table 2; Figure 5), where the MET condition had significantly less ankle dorsiflexion than the unlaced condition $\left(-1.7^{\circ} ; \mathrm{p}=0.006\right)$. Ankle frontal ROM (inversion/eversion) was also significantly different between footwear conditions $\left(\chi^{2}=12.33, p=.002\right.$; Table 4). Wilcoxon signed ranked tests revealed that both the work boot $(p=0.004)$ and MET $(p=0.007)$ footwear condition had significantly less frontal ROM than the unlaced condition.

Hip, knee, and upper back kinematics appeared to be unaffected by the different footwear conditions in any of the three dimensions (Tables 2-4). Likewise, low back angles (Table 5;

Figure 6) and velocities (Table 5) were similar between conditions and footwear did not seem to alter the magnitude of sagittal moments about the low back (Table 6; Figure 7).

No statistical differences were found for maximum and minimum low back net reaction moments in the sagittal, frontal, or transverse planes. Additionally, the maximum low back net reaction moments in the sagittal plane were statistically different between males and females $(\mathrm{F}=$ 53.88 $p<0.001, \eta^{2}=0.710$; Table 6). The significant difference between males and females for low back sagittal net reaction moments was still present when the data were normalized to bodyweight $\left(\mathrm{F}=14.80, p=0.001, \eta^{2}=.402\right)$, where males were had higher net reaction moments than females. 


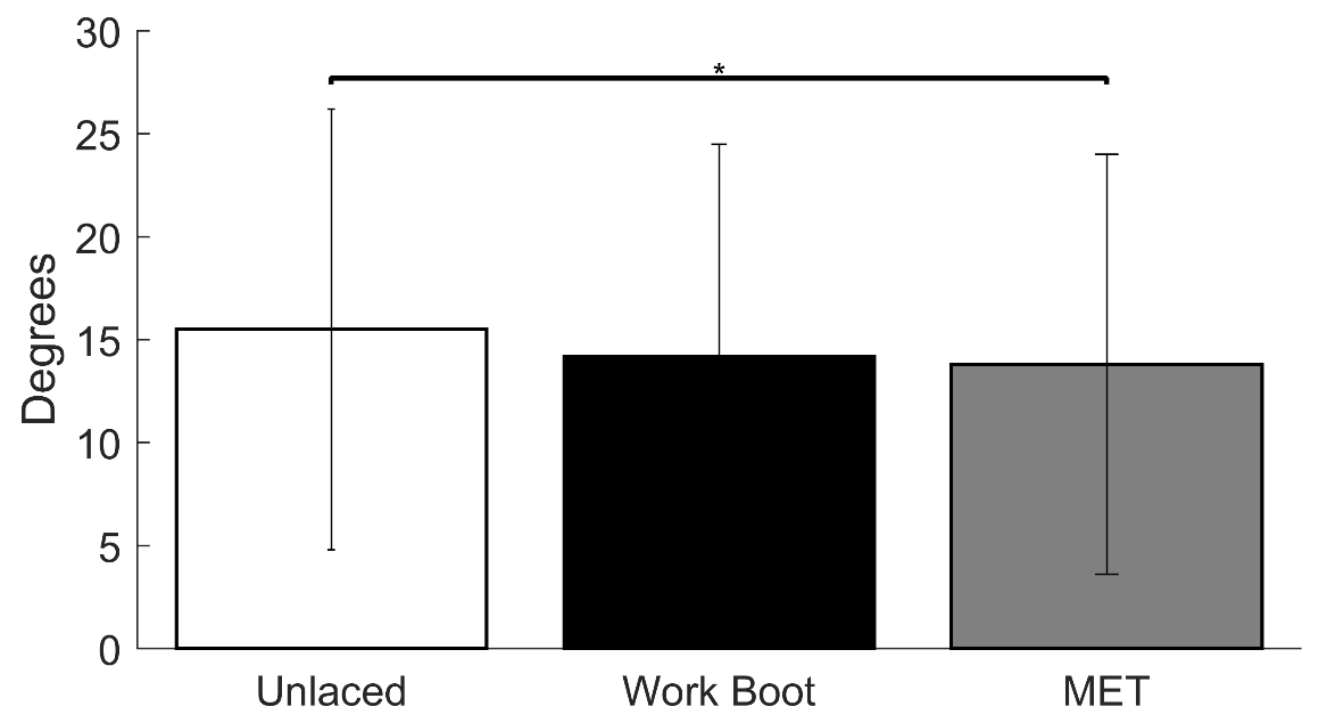

Figure 5. Maximum Ankle Dorsiflexion. Ankle dorsiflexion was significantly different between footwear conditions. The MET condition had significantly less dorsiflexion than the unlaced condition. Red lines represent each participant's data. Black bars with an asterisk represent significant differences between conditions. Error bars represent the standard deviation about the mean and the black horizontal bars represent significant differences between conditions at $p<0.01$.

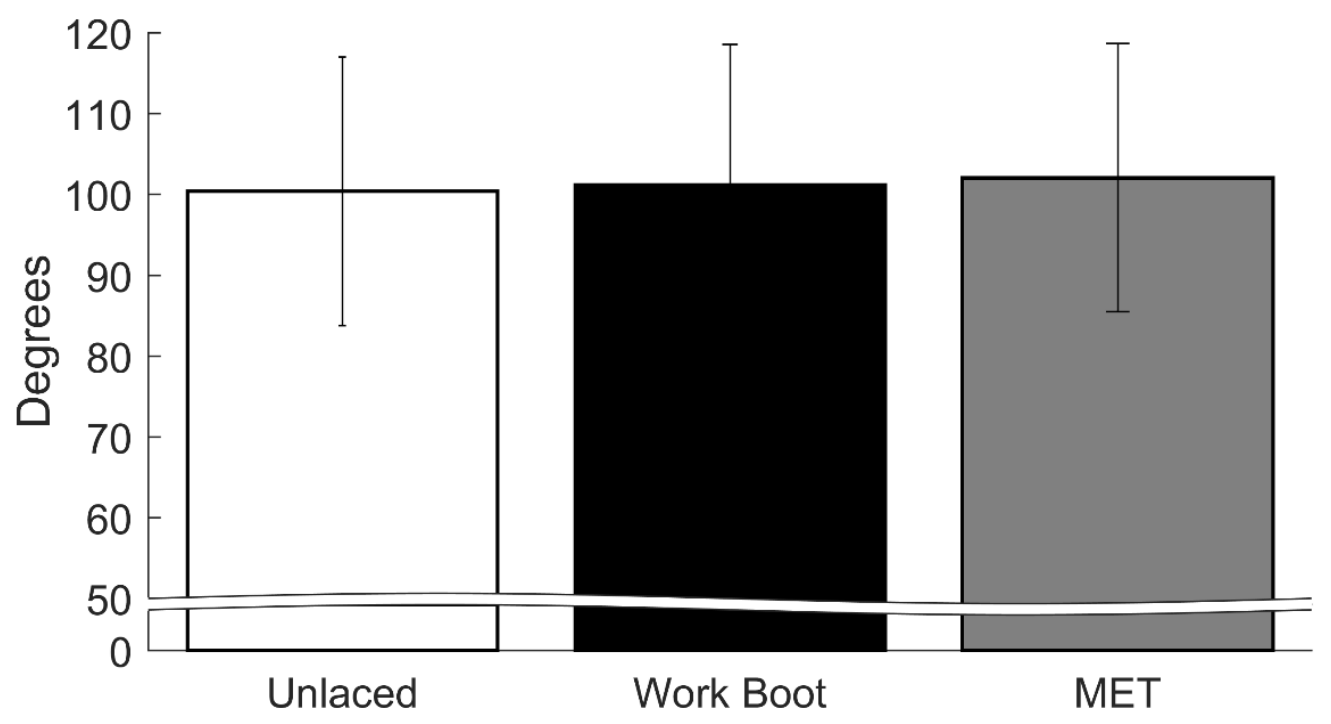

Figure 6. Maximum Lumbar Flexion. Different types of work boots did not result in significant differences in maximal lumbar flexion. However, there are slight increases in flexion angle as the ankle becomes more restricted. Error bars represent the standard deviation about the mean. 


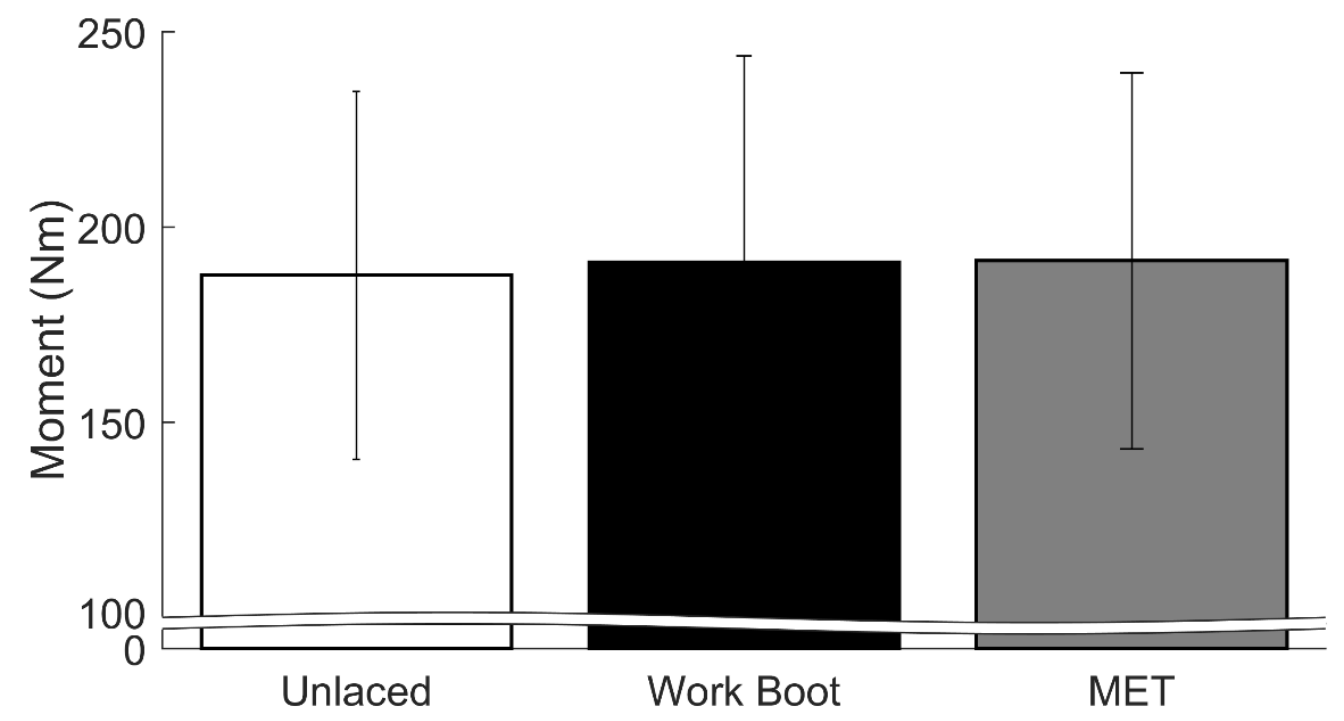

Figure 7. Maximum Sagittal Net Reaction Moments about the Low Back. Different types of protective footwear did not result in significant differences in sagittal moments. Error bars represent the standard deviation about the mean. 
Table 2. Sagittal Plane Kinematic Results.

\begin{tabular}{|c|c|c|c|c|c|c|c|c|c|c|c|c|c|c|c|c|c|c|}
\hline & \multirow[b]{3}{*}{ Joint } & \multirow{3}{*}{$\begin{array}{l}\text { Work Boot } \\
\text { Mean (SD) }\end{array}$} & \multirow{3}{*}{$\begin{array}{c}\text { Met } \\
\text { Mean (SD) }\end{array}$} & \multirow{3}{*}{$\begin{array}{c}\text { Unlace } \\
\text { Mean (SD) }\end{array}$} & \multirow{2}{*}{\multicolumn{3}{|c|}{$\begin{array}{c}\text { Between Subject Effects } \\
\text { Sex }\end{array}$}} & \multicolumn{9}{|c|}{ RM-ANOVA Results } & \multirow{2}{*}{\multicolumn{2}{|c|}{$\begin{array}{c}\text { Friedman Test } \\
\text { Shoe }\end{array}$}} \\
\hline & & & & & & & & & Shoe & & & Shoe*Se & & & Post-hoc & & & \\
\hline & & & & & $\begin{array}{c}\mathrm{F}- \\
\text { ratio }\end{array}$ & $\begin{array}{c}\mathrm{p}- \\
\text { value }\end{array}$ & $\eta 2$ & $\begin{array}{c}\mathrm{F}- \\
\text { ratio }\end{array}$ & $\begin{array}{c}\mathrm{p}- \\
\text { value }\end{array}$ & $\eta^{2}$ & $\begin{array}{l}\text { F- } \\
\text { ratio }\end{array}$ & $\begin{array}{c}\mathrm{p}- \\
\text { value }\end{array}$ & $\eta^{2}$ & $\begin{array}{l}\text { Lace vs. } \\
\text { MET }\end{array}$ & $\begin{array}{l}\text { Lace vs. } \\
\text { Unlace }\end{array}$ & $\begin{array}{l}\text { MET vs. } \\
\text { Unlace }\end{array}$ & $\mathrm{X}^{2}$ & $\begin{array}{c}\mathrm{p}- \\
\text { value }\end{array}$ \\
\hline \multirow{4}{*}{$\begin{array}{l}\text { Extension } \\
\qquad\left(^{\circ}\right)\end{array}$} & $\begin{array}{c}\text { Ankle } \\
\text { (Dorsiflexion) }\end{array}$ & $14.2(10.3)$ & $13.8(10.2)$ & $15.5(10.7)$ & 0.000 & 0.988 & 0.000 & 5.41 & 0.008 & 0.197 & 1.14 & 0.329 & 0.049 & 0.458 & 0.020 & 0.006 & & \\
\hline & Knee & $\begin{array}{l}-0.394 \\
(2.60)\end{array}$ & $0.176(2.28)$ & $0.291(3.34)$ & 0.111 & 0.742 & 0.005 & 1.01 & 0.373 & 0.044 & 1.22 & 0.305 & 0.053 & & & & & \\
\hline & Hip & $-11.6(6.73)$ & $-11.8(6.43)$ & $-11.3(7.12)$ & 0.301 & 0.589 & 0.013 & 0.549 & 0.581 & 0.024 & 0.206 & 0.814 & 0.009 & & & & & \\
\hline & Upper Back & $4.90(8.63)$ & $5.60(7.54)$ & $4.18(9.44)$ & 0.263 & 0.613 & 0.078 & 1.845 & 0.185 & 0.077 & 0.614 & 0.546 & 0.027 & & & & & \\
\hline \multirow{4}{*}{$\begin{array}{c}\text { Flexion } \\
\left({ }^{\circ}\right)\end{array}$} & $\begin{array}{l}\text { Ankle } \\
\text { (Plantar } \\
\text { Flexion) }\end{array}$ & $5.96(3.69)$ & $5.58(3.04)$ & $6.38(3.64)$ & 0.015 & 0.903 & 0.001 & 0.232 & 0.794 & 0.010 & 1.41 & 0.256 & 0.060 & & & & \multirow{3}{*}{\multicolumn{2}{|c|}{$\begin{array}{ll}1.75 & 0.417\end{array}$}} \\
\hline & Knee & $68.9(33.7)$ & $69.2(35.0)$ & $71.4(35.0)$ & 0.337 & 0.568 & 0.015 & 1.35 & 0.269 & 0.058 & 0.347 & 0.709 & 0.016 & & & & & \\
\hline & Upper Back & $-12.3(6.39)$ & $-12.2(6.24)$ & $-13.3(8.16)$ & & & & & & & & & & & & & & \\
\hline & Ankle & $20.3(9.61)$ & $20.1(9.70)$ & $21.6(10.4)$ & 0.003 & 0.959 & 0.000 & 4.33 & 0.019 & 0.164 & 1.61 & 0.211 & 0.068 & & & & & \\
\hline ROM & Knee & $68.5(32.9)$ & $64.4(34.4)$ & $71.7(34.0)$ & 0.323 & 0.576 & 0.014 & 2.11 & 0.133 & 0.087 & 0.122 & 0.885 & 0.006 & & & & & \\
\hline \multirow[t]{2}{*}{$\left({ }^{\circ}\right)$} & Hip & $54.6(10.8)$ & $54.7(11.1)$ & $54.6(11.3)$ & 0.174 & 0.681 & 0.008 & 0.017 & 0.983 & 0.001 & 2.29 & 0.114 & 0.094 & & & & & \\
\hline & Upper Back & $17.2(4.18)$ & $17.8(4.89)$ & $17.4(4.45)$ & 0.512 & 0.482 & 0.023 & 0.744 & 0.481 & 0.033 & 0.061 & 0.941 & 0.003 & & & & & \\
\hline
\end{tabular}

Bolded values represent statistical significance at $p<0.01 . S D=$ standard deviation. $M E T=$ a fully laced boot with a metatarsal guard. $R$ R-ANOVA = Repeated-measures analysis of variance. 
Table 3. Transverse Plane Kinematic Results.

\begin{tabular}{|c|c|c|c|c|c|c|c|c|c|c|c|c|c|c|c|}
\hline & \multirow[b]{3}{*}{ Joint } & \multirow{3}{*}{$\begin{array}{c}\text { Work Boot } \\
\text { Mean (SD) }\end{array}$} & \multirow{3}{*}{$\begin{array}{c}\text { Met } \\
\text { Mean (SD) }\end{array}$} & \multirow{3}{*}{$\begin{array}{c}\text { Unlace } \\
\text { Mean (SD) }\end{array}$} & \multirow{2}{*}{\multicolumn{3}{|c|}{$\begin{array}{c}\text { Between Subject Effects } \\
\text { Sex }\end{array}$}} & \multicolumn{6}{|c|}{ RM-ANOVA Results } & \multirow{2}{*}{\multicolumn{2}{|c|}{$\begin{array}{c}\text { Friedman Test } \\
\text { Shoe }\end{array}$}} \\
\hline & & & & & & & & & Shoe & & & Shoe*Sex & & & \\
\hline & & & & & F-ratio & p-value & $\eta 2$ & F-ratio & p-value & $\eta^{2}$ & F-ratio & p-value & $\eta 2$ & $\mathrm{X}^{2}$ & $\mathrm{p}$-value \\
\hline \multirow{4}{*}{$\begin{array}{c}\text { Internal Rotation } \\
\qquad\left(^{\circ}\right)\end{array}$} & Ankle & $3.19(3.01)$ & $3.48(2.95)$ & $3.38(3.51)$ & 0.205 & 0.655 & 0.009 & 0.415 & 0.663 & 0.019 & 0.034 & 0.967 & 0.002 & \multirow{4}{*}{3.00} & \multirow{4}{*}{0.223} \\
\hline & Knee & $9.40(1.20)$ & $9.58(1.49)$ & $10.3(1.53)$ & & & & & & & & & & & \\
\hline & Hip & $0.864(7.11)$ & $1.33(7.64)$ & 1.577 (7.77) & 0.564 & 0.461 & 0.025 & 1.51 & 0.232 & 0.064 & 1.09 & 0.345 & 0.047 & & \\
\hline & Upper Back (Left) & $2.21(2.65)$ & $2.56(2.53)$ & $2.32(2.62)$ & 0.351 & 0.560 & 0.016 & 2.570 & 0.088 & 0.105 & 2.181 & 0.125 & 0.090 & & \\
\hline \multirow{3}{*}{$\begin{array}{c}\text { External Rotation } \\
\qquad\left(^{\circ}\right)\end{array}$} & Ankle & $1.79(1.91)$ & $1.59(2.19)$ & $2.32(2.18)$ & 3.34 & 0.081 & 0.132 & 3.361 & 0.044 & 0.133 & 1.56 & 0.221 & 0.066 & & \\
\hline & Knee & $2.98(2.81)$ & $3.82(2.85)$ & 3.094 (2.49) & 0.062 & 0.805 & 0.003 & 4.17 & 0.022 & 0.159 & 1.35 & 0.270 & 0.058 & & \\
\hline & Hip & $11.4(6.32)$ & $11.4(6.40)$ & $11.40(6.34)$ & 0.256 & 0.618 & 0.012 & 0.005 & 0.995 & 0.00 & 0.971 & 0.387 & 0.042 & & \\
\hline \multirow{4}{*}{$\begin{array}{l}\text { ROM } \\
\left(^{\circ}\right)\end{array}$} & Ankle & $4.97(0.418)$ & $5.06(0.449)$ & $5.69(0.591)$ & & & & & & & & & & 1.33 & 0.513 \\
\hline & Knee & $12.4(1.02)$ & $13.4(1.57)$ & $13.4(1.61)$ & & & & & & & & & & 1.08 & 0.582 \\
\hline & Hip & $12.3(0.652)$ & $12.8(0.878)$ & $13.0(0.919)$ & & & & & & & & & & 2.33 & 0.311 \\
\hline & Upper Back & $6.20(1.31)$ & $6.59(1.41)$ & $6.57(1.78)$ & 0.050 & 0.825 & 0.002 & 1.947 & 0.155 & 0.081 & 1.573 & 0.219 & 0.067 & & \\
\hline
\end{tabular}

Bolded values represent statistical significance at $p<0.01 . S D=$ standard deviation. MET = a fully laced boot with a metatarsal guard. RM-ANOVA = Repeated-measures analysis of variance. 
Table 4. Frontal Plane Kinematic Results.

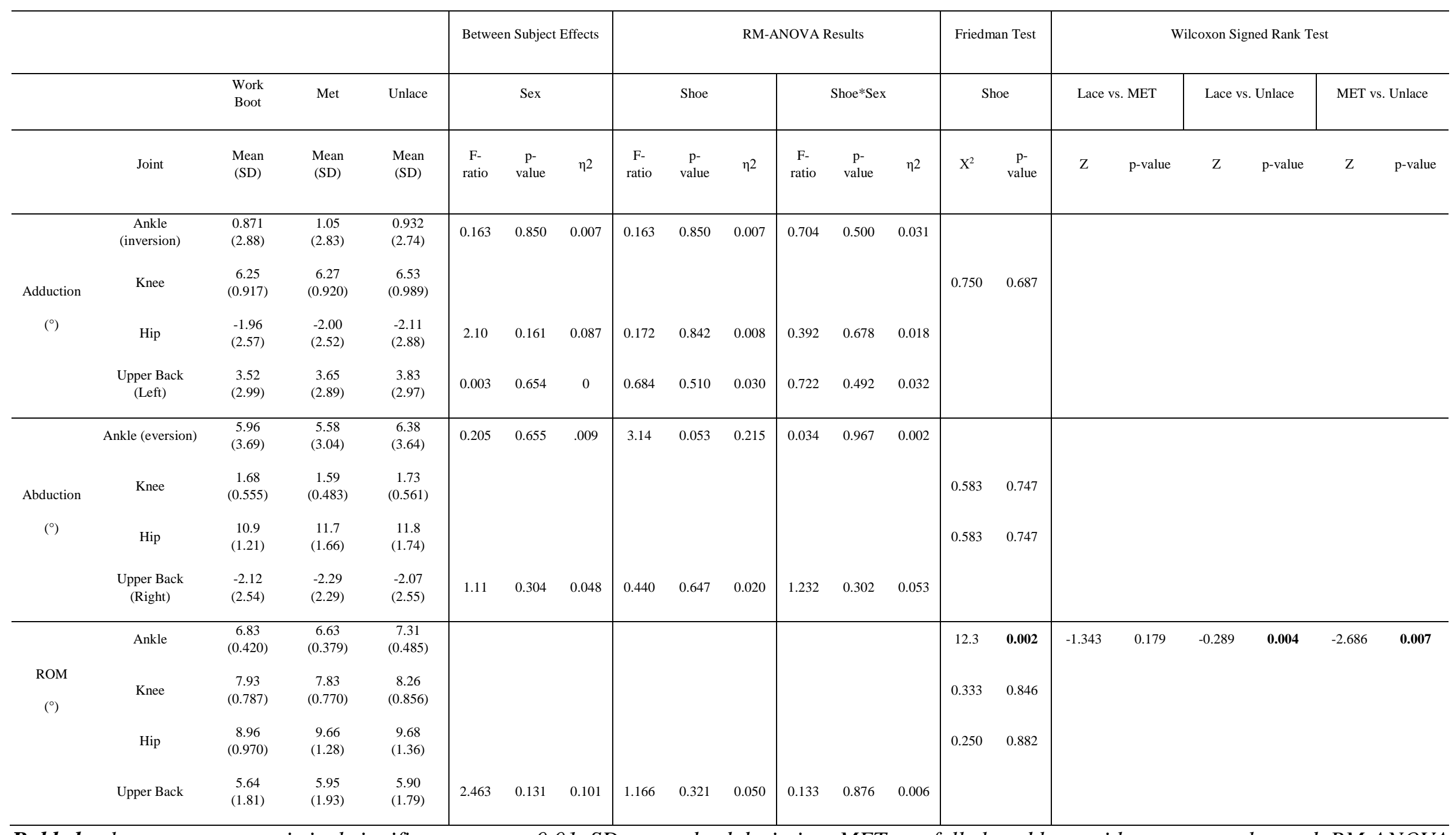

Bolded values represent statistical significance at $p<0.01 . S D=$ standard deviation. $M E T=$ a fully laced boot with a metatarsal guard. RM-ANOVA $=$ Repeated-measures analysis of variance. 
Table 5. Low Back Kinematic Results.

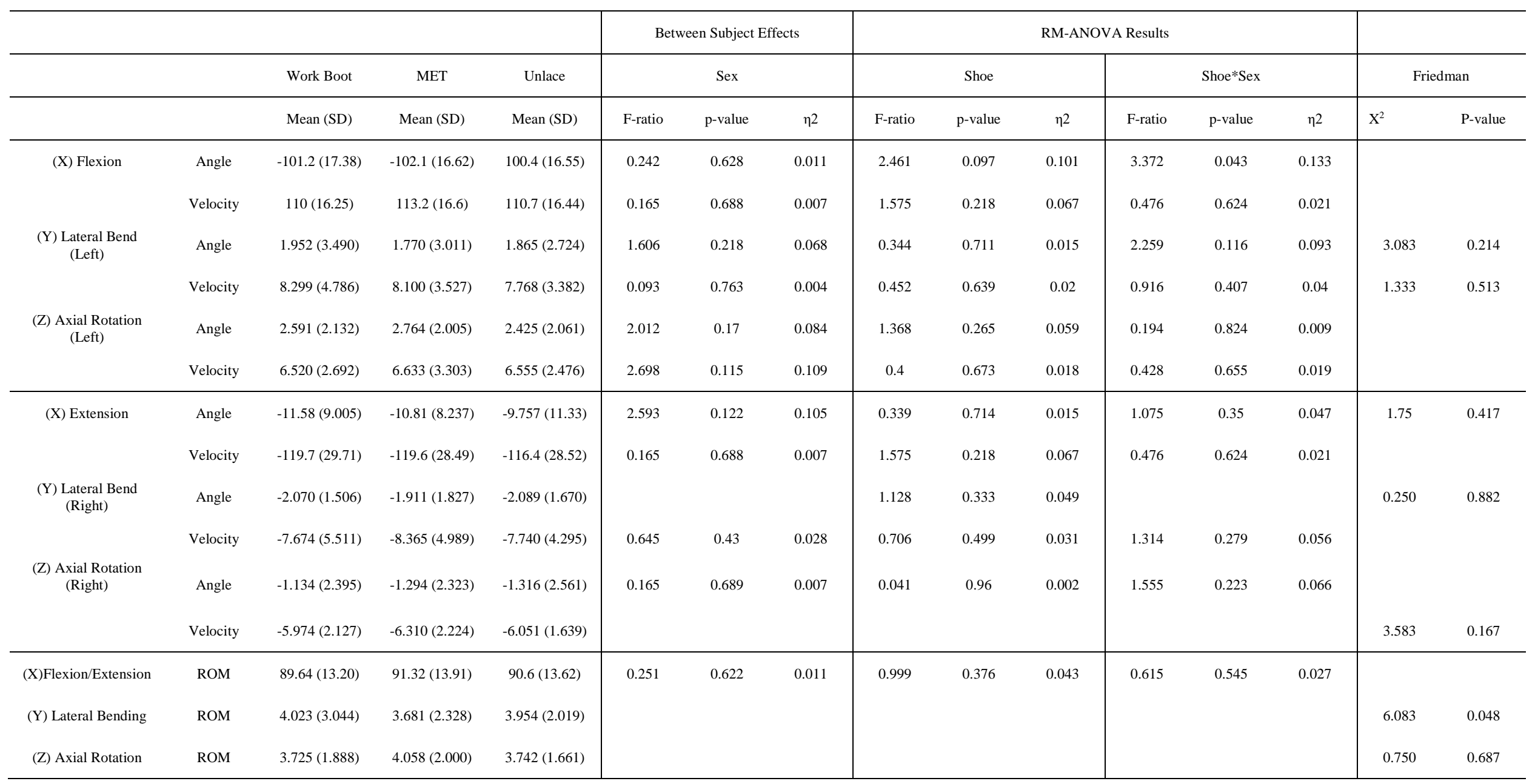

Bolded values represent statistical significance at $p<0.01 . S D=$ standard deviation. MET = a fully laced boot with a metatarsal guard. RM-ANOVA = Repeated-measures analysis of variance. 
Table 6. Low Back Kinetic Results.

\begin{tabular}{|c|c|c|c|c|c|c|c|c|c|c|c|c|c|c|c|c|c|c|c|c|c|}
\hline & & \multirow{3}{*}{$\begin{array}{l}\text { Work Boot } \\
\text { Mean (SD) }\end{array}$} & \multirow{3}{*}{$\frac{\text { MET }}{\text { Mean (SD) }}$} & \multirow{3}{*}{$\begin{array}{c}\text { Unlace } \\
\text { Mean (SD) }\end{array}$} & \multirow{2}{*}{\multicolumn{3}{|c|}{$\frac{\text { Between Subject Effects }}{\text { Sex }}$}} & \multicolumn{6}{|c|}{ RM-ANOVA Results } & \multicolumn{6}{|c|}{ Within Subject Contrasts } & & \\
\hline & & & & & & & & \multicolumn{3}{|c|}{ Shoe } & \multicolumn{3}{|c|}{ Shoe*Sex } & \multicolumn{3}{|c|}{ Lace vs. MET } & \multicolumn{3}{|c|}{ MET vs. Unlace } & \multicolumn{2}{|c|}{ Friedman } \\
\hline & & & & & $\begin{array}{c}\mathrm{F}- \\
\text { ratio }\end{array}$ & $\begin{array}{c}\mathrm{p}- \\
\text { value }\end{array}$ & $\eta 2$ & $\begin{array}{c}\mathrm{F}- \\
\text { ratio }\end{array}$ & $\begin{array}{c}\mathrm{p}- \\
\text { value }\end{array}$ & $\eta^{2}$ & $\begin{array}{c}\mathrm{F}- \\
\text { ratio }\end{array}$ & $\begin{array}{c}\mathrm{p}- \\
\text { value }\end{array}$ & $\eta^{2}$ & $\begin{array}{c}\mathrm{F}- \\
\text { ratio }\end{array}$ & $\begin{array}{c}\mathrm{p}- \\
\text { value }\end{array}$ & $\eta^{2}$ & $\begin{array}{c}\text { F- } \\
\text { ratio }\end{array}$ & $\begin{array}{c}\mathrm{p}- \\
\text { value }\end{array}$ & $\eta^{2}$ & $\mathrm{X}^{2}$ & $\begin{array}{c}\mathrm{p}- \\
\text { value }\end{array}$ \\
\hline \multirow{3}{*}{$\begin{array}{l}\text { Maximum } \\
\text { Moment } \\
(\mathrm{Nm})\end{array}$} & Sagittal & $-191.0(52.87)$ & $-191.4(48.12)$ & $-187.7(47.08)$ & 53.88 & $<0.001$ & 0.710 & 2.398 & 0.103 & 0.098 & 5.131 & 0.010 & 0.198 & 3.805 & 0.064 & 0.147 & 2.011 & 0.170 & 0.084 & & \\
\hline & Frontal & $6.277(6.912)$ & $6.902(7.095)$ & $6.404(6.485)$ & 2.094 & 0.162 & 0.087 & 0.213 & 0.809 & 0.01 & 1.959 & 0.153 & 0.082 & & & & & & & & \\
\hline & Transverse & $5.870(3.412)$ & $5.937(3.216)$ & $5.818(3.334)$ & & & & & & & & & & & & & & & & 1.583 & 0.453 \\
\hline \multirow{3}{*}{$\begin{array}{l}\text { Minimum } \\
\text { Moment } \\
(\mathrm{Nm})\end{array}$} & Sagittal & $-0.086(10.28)$ & $1.017(10.23)$ & $0.5245(10.55)$ & 6.56 & 0.018 & 0.23 & 1.426 & 0.251 & 0.061 & 0.428 & 0.654 & 0.019 & & & & & & & & \\
\hline & Frontal & $-4.565(3.663)$ & $-4.515(4.320)$ & $-4.790(3.891)$ & & & & 0.57 & 0.569 & 0.024 & & & & & & & & & & & \\
\hline & Transverse & $-2.160(4.121)$ & $-1.566(3.635)$ & $-1.876(3.673)$ & 0.571 & 0.458 & 0.025 & 0.095 & 0.91 & 0.004 & 0.668 & 0.518 & 0.029 & & & & & & & & \\
\hline
\end{tabular}

Note: statistics were run on normalized data (\% body weight). Raw numbers are presented in the mean. Bolded values represent statistical significance at $p<0.01 . S D=$ standard deviation. MET = a fully laced boot with a metatarsal guard. RM-ANOVA = Repeated-measures analysis of variance. 


\subsection{Local Dynamic Stability}

LDS was unchanged in the lower or upper back segment (Figure 8-9; Table 7) between footwear conditions. Additionally, LDS was unchanged within any of other segments going up the kinematic chain between footwear conditions (Figure 10). However, as observed in Figure 10, $\lambda_{\max }$ values increased (less stable) and displayed more variability between conditions when going up the kinematic chain (i.e. low back and upper back).

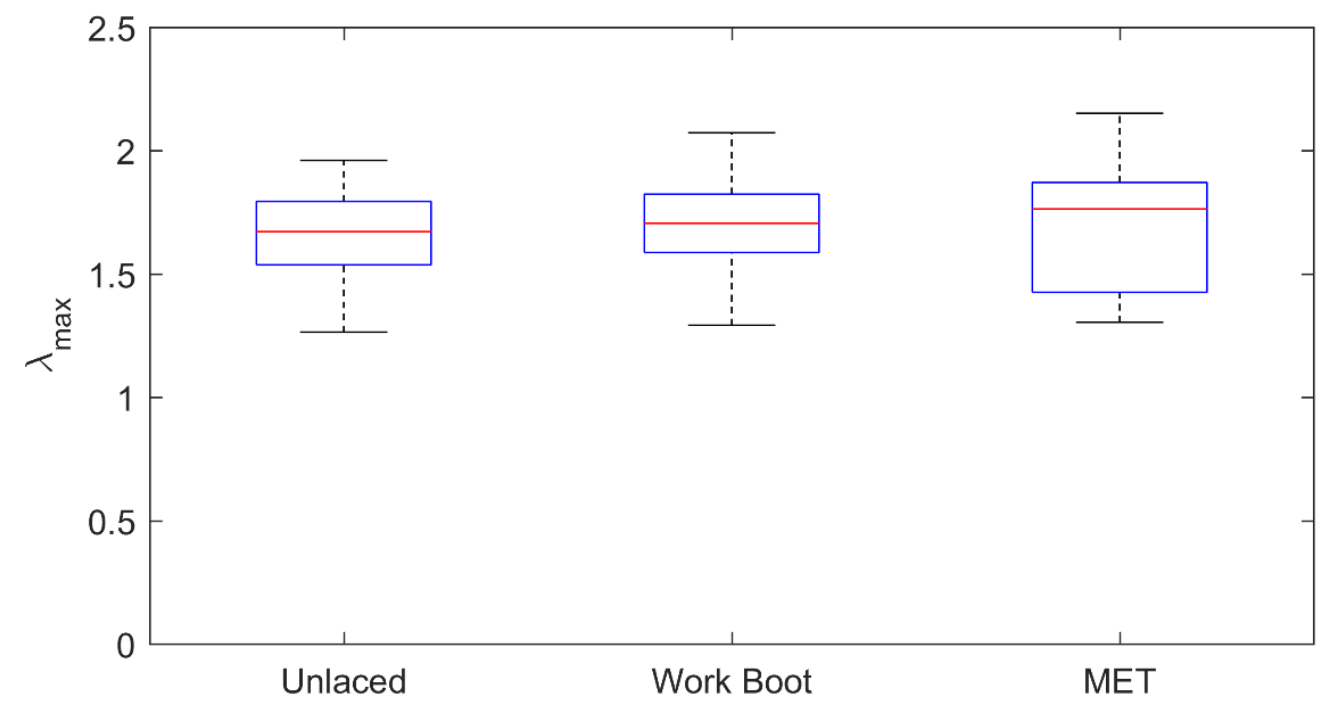

Figure 8. Low Back Local Dynamic Stability Results. Box-whisker plots represent the data range, where the box represents the data within the first and third quartiles (i.e. 25\%-75\%), the red line represents the median, and the black lines represents the highest and lowest observed values. 


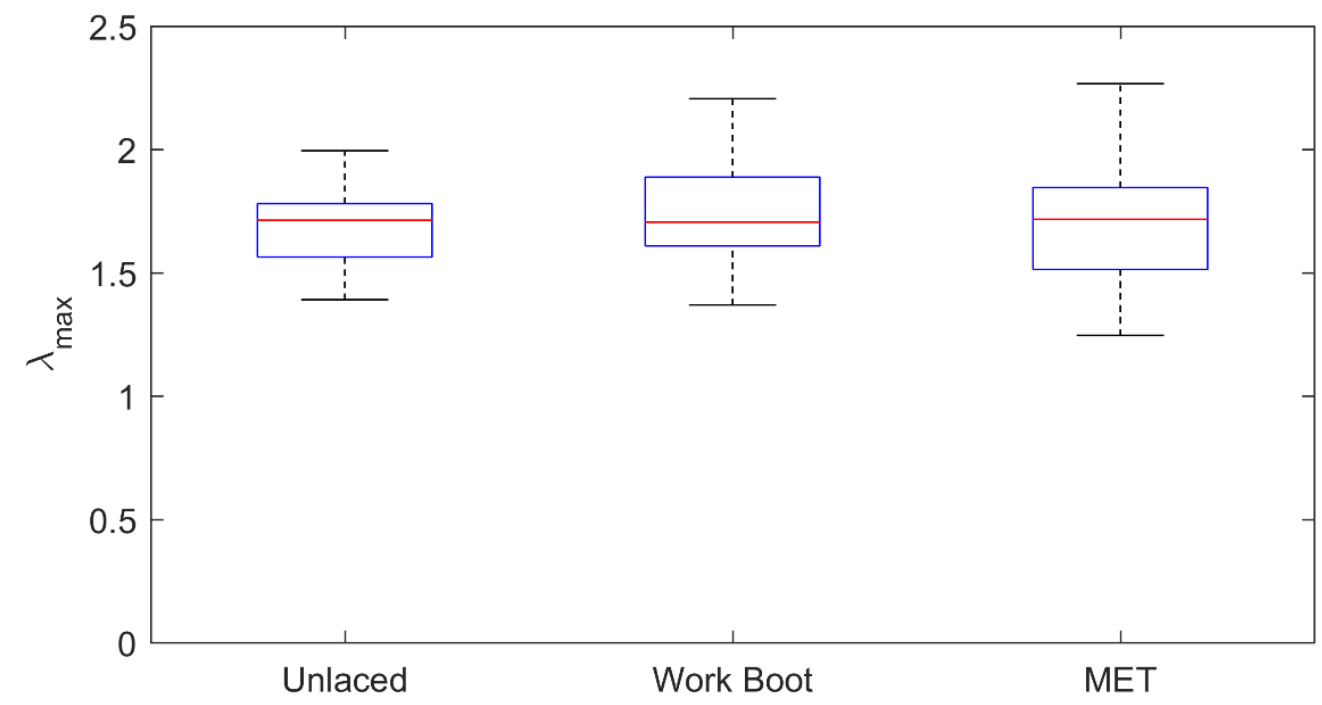

Figure 9. Upper Back Local Dynamic Stability Results. Box-whisker plots represent the data range, where the box represents the data within the first and third quartiles (i.e. $25 \%-75 \%$ ), the red line represents the median, and the black lines represents the highest and lowest observed values.

Table 7. Lower and Upper Back Local Dynamic Stability Results.

\begin{tabular}{|c|c|c|c|c|c|c|c|c|c|c|c|c|}
\hline & \multirow{3}{*}{$\begin{array}{l}\text { Work Boot } \\
\text { Mean (SD) }\end{array}$} & \multirow{3}{*}{$\begin{array}{c}\text { MET } \\
\text { Mean (SD) }\end{array}$} & \multirow{3}{*}{$\begin{array}{c}\text { Unlaced } \\
\text { Mean (SD) }\end{array}$} & \multirow{2}{*}{\multicolumn{3}{|c|}{$\begin{array}{c}\text { Between Subject Effects } \\
\text { Sex }\end{array}$}} & \multicolumn{6}{|c|}{ RM-ANOVA Results } \\
\hline & & & & & & & \multicolumn{3}{|c|}{ Shoe } & \multicolumn{3}{|c|}{ Shoe*Sex } \\
\hline & & & & F-ratio & p-value & $\eta 2$ & F-ratio & p-value & $\eta 2$ & F-ratio & p-value & $\eta 2$ \\
\hline Low Back & $1.740(0.2264)$ & $1.696(0.2497)$ & $1.701(0.2249)$ & 0.986 & 0.332 & 0.043 & 0.948 & 0.395 & 0.041 & 0.907 & 0.411 & 0.040 \\
\hline Upper Back & $1.769(0.2643)$ & $1.713(0.2761)$ & $1.695(0.2596)$ & 0.820 & 0.375 & 0.036 & 2.030 & 0.143 & 0.084 & 1.522 & 0.230 & 0.065 \\
\hline
\end{tabular}

No statistical differences were observed for $\lambda_{\max }$ values in the upper or lower back. SD = standard deviation. MET $=$ a fully laced boot with a metatarsal guard. RM-ANOVA = Repeated-measures analysis of variance. 


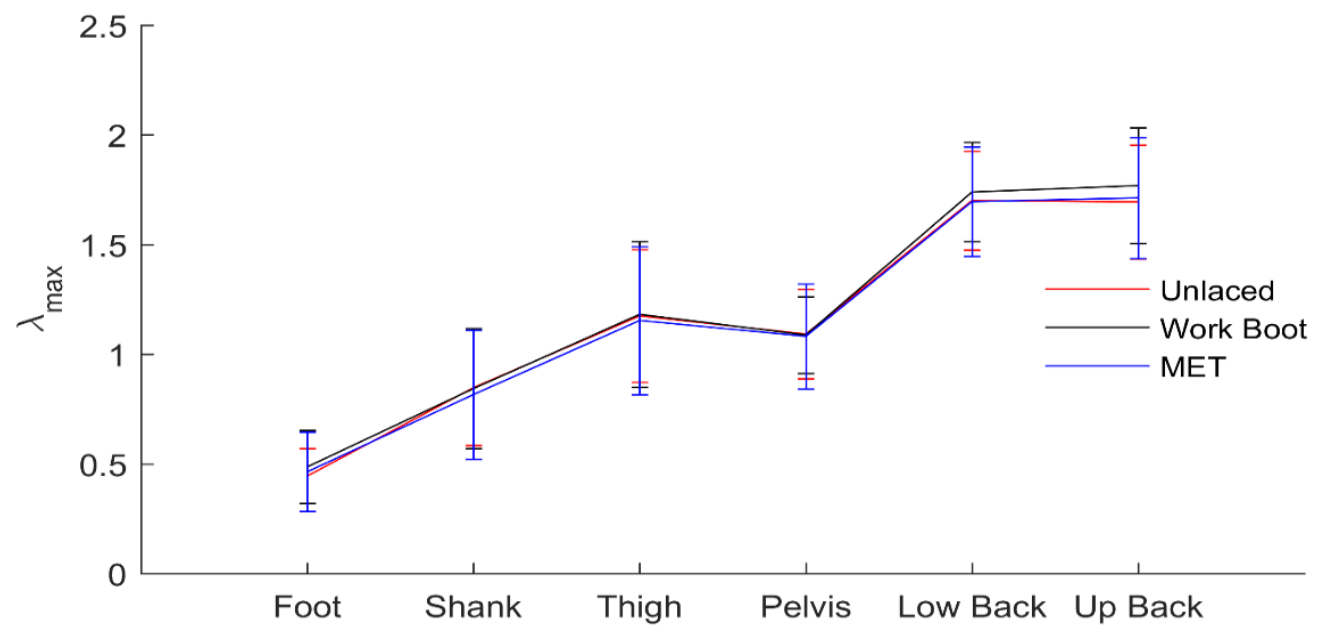

Figure 10. Kinematic Chain Dynamic Stability Results. Local dynamic stability measures were unchanged between protective footwear conditions. Although non-significant, higher up the kinematic chain appears to have been more affected by the reduction in ankle mobility. Error bars represent the standard deviation about the mean.

\section{CHAPTER 5: DISCUSSION}

The purpose of this thesis was to analyze the effects of different types of protective footwear (i.e. works shoes, work boots, and work boots with a metatarsal guard) on lifting mechanics during a sagittal lifting task. This was done to determine if the added protection provided to workers through PPE alters how people perform MMH tasks. It was hypothesized that the restrictive nature of the boots would decrease ankle mobility, which would then induce changes to participants' low back flexion angles and moments, and their LDS going up the kinematic chain.

As hypothesized, the kinematics of the ankle were influenced by the different types of protective footwear, where the MET condition had significantly less ankle dorsiflexion than the unlaced condition $\left(p=0.006 ;-1.7^{\circ} ; \beta=0.82\right.$; Table 2$)$ and both the work boot and MET conditions had significantly less ankle frontal ROM (inversion/eversion) than the unlaced condition (work boot: $p=0.004,-0.48^{\circ}$; MET: $p=0.007,-0.68^{\circ}$; Table 4). However, since these values are less than $1^{\circ}$ and our power to detect these differences was low $(\beta=0.07)$, some of these results may be due to measurement error (Andersen, Benoit, Damsgaard, Ramsey, \& Rasmussen, 2010; Benoit et 
al., 2006). Nevertheless, our sagittal results are similar to what has been reported previously by Blench (1998), who observed a $3^{\circ}$ decrease in ankle angle in the sagittal plane during a lifting task while wearing work boots compared to flat shoes, and what has been reported in gait literature: an increase in boot stiffness decreases ankle ROM in the sagittal plane when wearing hiking boots (Böhm \& Hösl, 2010) and military boots (Cikajlo \& Matjacić, 2007). Contrary to what was hypothesized, in the present study the addition of a metatarsal guard did not influence the ankle's mobility to a significantly greater extent than wearing normal work boots. Therefore, it appears that the additional material around the ankle (the upper) affects the mobility of the ankle the most during lifting tasks, while metatarsal guards have a minimal additional effect on the ankle. The decrease in ankle mobility that was observed in the present thesis did not lead to any other significant changes to the other kinematic variables analyzed.

Contrary to the second hypothesis, sagittal net reaction moments about the low back were statistically similar between conditions (Figure 7). On average, sagittal net reaction moments about the low back had a small increase of $\sim 3.7 \mathrm{Nm}$ in the MET condition and $\sim 3.3 \mathrm{Nm}$ in the work boot condition when compared to the unlaced condition. It is possible that as the ankle became more restricted, participants non-significantly increased their sagittal low back angle, which resulted in the slight increase of sagittal net moments about the low back (e.g. Hoozemans et al., 2008; Lavender et al., 2003). Post-hoc power calculations suggest that the sagittal net reaction moment and, to a greater extent, the low back angle variables were underpowered to detect differences between footwear conditions (moments: $\beta=0.707$; maximum sagittal low back angle: $\beta=0.466$ ); therefore, future research should incorporate a larger sample size than the one presented in this thesis. 
Local dynamic stability of the segments tested (i.e. feet, shanks, thighs, pelvis, low back, upper back) were unchanged by protective footwear type; the third hypothesis was therefore rejected. Post-hoc power calculations suggest that $\lambda_{\max }$ values were slightly under powered $(\beta=$ 0.664). However, as hypothesized, stability decreased going up the kinematic chain (i.e. low back and upper back; Graham, Costigan, Sadler, \& Stevenson, 2011). Although $\lambda_{\max }$ values were more variable at the highest levels of the kinematic chain, there was no main effect of footwear on their stability values (Figure 10). It is possible that participants were able to make the appropriate postural adjustments through a complex series of muscle activations and employing strategies such as co-contraction to increase their mechanical joint stability, which could result in unchanged LDS between conditions (Brown, Vera-Garcia, \& McGill, 2006; Graham \& Brown, 2012). This hypothesis should be explored in the future because there is a trade-off between spinal stability and spinal loading (Cholewicki \& McGill, 1996): when the muscles of the back become more active to stiffen and stabilize the spine, it increases the magnitude of spinal loads (Granata \& Marras, 1995; McGill, 1992; van Dieën \& Kingma, 1999).

It is well established that there are physiological and anatomical differences between males and females. However, in this investigation, sex did not appear to be a significant contributor to changes in lifting mechanics between protective footwear conditions. The only main effect of sex was found for the maximum net reaction moment about the low back, where males had significantly higher net reaction moments than females. Since males are oftentimes heavier than females, the net reaction moments were normalized to a percentage of bodyweight. Results on the normalized data elicited the same outcome: males had a significantly higher sagittal net reaction moment about the low back than females (Table 6). A possible mechanistic factor could be that the males in the present thesis were stronger than their female counterparts. Having a greater 
amount of strength would allow the males to lift a higher percentage of their body mass than the females. This larger relative mass would cause a greater downward force that the males would need to compensate for. However, lifting a heavier load did not appear to greatly alter the lifting kinematics between sexes; the lack of significant differences between male and female lifting mechanics may be explained by the normalized weight lifted (e.g. Sadler, Graham, \& Stevenson, 2011, 2013). If the load is not normalized, the weight may be too heavy for some and too light for others, rather than each participant exerting a similar amount of relative effort. Therefore, to make a fair comparison, it is important to normalize the weight lifted to each participant's capabilities (Sadler et al., 2013). In the present thesis, the weight lifted was normalized to $10 \%$ of the participant's maximum back strength, which elicited similar lifting mechanics between sexes. This is in line with what Sadler et al. (2013) found: there are no sex differences in lifting mechanics when lifting at 0 and $10 \%$ of maximum back strength. Therefore, the findings of the present thesis suggest that males and females not only lift in a similar fashion, they also adapt their lifting mechanics in a similar way when wearing different types of protective footwear.

Fully lacing the work boots and attaching a metatarsal guard restricted the dorsiflexion of the ankle by $\sim 1.5^{\circ}$ (Figure 5). This amount of decreased mobility did not appear to affect the other parts of the body; participants were able to adequately accommodate the material restriction about the ankle. These findings are in agreement with what Blench (1998) found during a similar investigation: a small reduction $\left(3^{\circ}\right)$ in ankle dorsi/plantar flexion with no changes to lower limb kinematics. Blench (1998) did, however, note a change in trunk inclination angle when wearing work boots: participants tended to extend their buttocks behind them causing their trunk to be more parallel to the floor. Additionally, Blench (1998) had detected differences in muscle activation profiles in both the lower limbs and back. In the work boot condition, the tibialis anterior, 
multifidus, longissimus thoracic, and biceps femoris all elicited higher levels of activation (Blench, 1998). These increases in muscle activation may explain why no differences were observed in LDS for any of the segments measured in the present study. When muscle activity increases around a given joint it increases the mechanical stability of that joint (Brown \& McGill, 2010). Therefore, it is possible that participants elicited larger amounts of muscle activity in the present study to increase their mechanical joint stability, which directly relates to an increase in LDS (Graham \& Brown, 2012); this hypothesis will be explored in the future.

In a similar investigation, Beach et al. (2014) unilaterally immobilized their participant's ankle with an ankle brace, which resulted in a $\sim 24^{\circ}$ decrease in sagittal ROM. In their symmetrical lifting protocol, the limited ankle mobility resulted in significantly less knee and greater lumbar sagittal ROM, causing higher anterior/posterior shear on the $\mathrm{L}_{4} / \mathrm{L}_{5}$ spinal segment. Although only a small increase in lumbar flexion $\left(\sim 3^{\circ}\right)$ was observed, this resulted in $\sim 100 \mathrm{~N}$ increase in $\mathrm{L}_{4} / \mathrm{L}_{5}$ anterior/posterior shear force (Beach et al., 2014). In the present investigation, the work boot and MET footwear conditions did not restrict the ankle nearly as much as what was imposed by Beach and colleagues $\left(\sim 1.5^{\circ}\right.$ vs $\left.\sim 24^{\circ}\right)$; however, participants increased their lumbar flexion angle in the MET condition by $\sim 1.8^{\circ}$ on average, just over half the value reported by Beach et al. (2014). Therefore, it is possible that as footwear becomes more restrictive (e.g. through differences in material stiffness or a higher upper), participants may increase their lumbar flexion angles and spinal loading parameters could become significantly higher (e.g. Hoozemans et al., 2008).

Overall, lifting mechanics were similar throughout the different protective footwear conditions, despite the reduction in ankle dorsiflexion in the MET condition. To maintain similar movement strategies, participants may have altered their muscle activation patterns similar to what was observed by Blench (1998). Although this coping strategy is beneficial for controlling one's 
movements, increasing the muscular activation in the back can be detrimental to spine health. As the muscles produce more force to stiffen the spine, they inadvertently produce higher amounts of compression and shear forces on the spine itself (Hodges et al., 2009; Marras et al., 2004). As observed by Beach et al. (2014) an increase of $\sim 3^{\circ}$ of trunk flexion leads to increases in $\mathrm{L}_{4} / \mathrm{L}_{5}$ shear forces of $\sim 100 \mathrm{~N}$. Although in the present study an increase of only $1.6^{\circ}$ of trunk flexion was observed, and sagittal net reaction moments about the low back were similar between footwear conditions (unlaced: $188 \mathrm{Nm}$; work boot: $190 \mathrm{Nm}$; MET: $191.4 \mathrm{Nm}$ ), follow-up analyses will be conducted to assess changes in compression and shear forces in the $\mathrm{L}_{4} / \mathrm{L}_{5}$ spinal segment. To do this, the data collected in the present study will be processed through an EMG-driven model (e.g. McGill, 1992) and a full body lumbar spine model in OpenSim (Beaucage-Gauvreau et al., 2017).

Several limitations are present in this study. The metatarsal guard used in this experiment, although conforming to specifications put out by the American Society for Testing and Materials (ASTM), does not conform to CSA standards, which states that metatarsal guards need to be an integral part of the work boot, such that the metatarsal guard must be attached to the boot (CSA Standard Z195-02). It was decided to test the MET condition with the removable metatarsal guards to decrease error that would be created by having participants physically change shoes (i.e. calibration error and changes due to material stiffness and heel drop). Another similar limitation is that participants did not wear steel-toed shoes. The steel-toed shoe condition was simulated by unlacing the boots to the level of the ankle, with the experimenter pulling the boot's tongue forward. This limitation was introduced to reduce the amount of error that would be caused by changing shoes, as described above. As mentioned, since only one style of work boot was tested, it is unknown if differences in material or changes to upper height impact lifting mechanics. Furthermore, all participants were healthy university students, the majority of which expressed 
that they had never worn steel-toed work boots before and had limited experience performing jobs that involved manual materials handling. It is possible that individuals who have LBP or those who routinely wear work boots and perform MMH tasks could react differently than the population tested. A relatively small sample size contributed to low power for some variables. More participants should be collected in future investigations to be able to detect small differences within variables. Finally, reflective markers were placed on the outside of the work boot, thus potentially inducing measurement error in the tracking of the foot. However, the presented ankle results in the sagittal plane were calculated to have a sufficiently high power $(\beta=0.820)$, instilling confidence that the small differences detected were indeed present.

\section{CHAPTER 6: CONCLUSION}

Wearing work boots with a metatarsal guard leads to a significant reduction of dorsiflexion (MET: $-1.7^{\circ}$ ) and both work boots with and without a metatarsal guard leads to a less than $1^{\circ}$ change in frontal plane ankle ROM. However, participants were able to appropriately adapt to this restricted ankle mobility during the repetitive lifting protocol. Although participants had slight, non-significant changes in their lifting mechanics, no clear differences were observed going up the kinematic chain in any of the variables tested. Likewise, there were no clear differences between males and females for any kinematic variable; however, males did exhibit higher net reaction moments about the low back than the females. With the present results it does not appear that wearing steel-toed work boots (with and without a metatarsal guard) changes the mechanics of lifting when compared to wearing steel-toed work shoes.

To maintain similar lifting mechanics between footwear types, participants may have altered their muscle activity to compensate for the reduction in ankle mobility, allowing them to maintain their kinematics and stability going up the kinematic chain. Although this type of coping 
strategy is beneficial for maintaining stability and kinematics, it may impose additional forces onto the lifter's spine. Therefore, follow-up analyses will assess if there are any alterations in muscle activity between footwear conditions and if these changes lead to increases in $\mathrm{L}_{4} / \mathrm{L}_{5}$ compression and shear forces. This will be done by processing the data from the present study using an EMGdriven model and a full body lumbar spine model in OpenSim. 


\section{CHAPTER 7: REFERENCES}

Andersen, M. S., Benoit, D. L., Damsgaard, M., Ramsey, D. K., \& Rasmussen, J. (2010). Do kinematic models reduce the effects of soft tissue artefacts in skin marker-based motion analysis? An in vivo study of knee kinematics. Journal of Biomechanics, 43(2), 268-273.

Bauer, C. M., Heimgartner, M., Rast, F. M., Ernst, M. J., Oetiker, S., \& Kool, J. (2015). Reliability of lumbar movement dysfunction tests for chronic low back pain patients. Manual Therapy, 24(April), 81-84.

Beach, T. A. C., Frost, D. M., Clark, J. M., Maly, M. R., \& Callaghan, J. P. (2014). Unilateral ankle immobilization alters the kinematics and kinetics of lifting. Work, 47(2), 221-234.

Beach, T. A. C., Frost, D. M., McGill, S. M., \& Callaghan, J. P. (2014). Physical fitness improvements and occupational low-back loading - an exercise intervention study with firefighters. Ergonomics, 57(5), 744-763.

Beaucage-Gauvreau, E., Thewlis, D., Graham, R. B., Roberston, W. S. P., Fraser, R. D., Freeman, B. J. C., \& Jones, C. F. (2017). Validation of full body OpenSim model with detailed lumbar spine to evaluate biomechanics of lifting tasks. In XXVI International Society of Biomechanics (p. 1).

Beaudette, S. M., Graham, R. B., \& Brown, S. H. M. (2014). The effect of unstable loading versus unstable support conditions on spine rotational stiffness and spine stability during repetitive lifting. Journal of Biomechanics, 47(2), 491-496.

Bennell, K. L., Talbot, R. C., Wajswelner, H., Techovanich, W., Kelly, D. H., \& Hall, A. J. (1998). Intra-rater and inter-rater reliability of a weight-bearing lunge measure of ankle dorsiflexion. The Australian Journal of Physiotherapy, 44(3), 175-180.

Benoit, D. L., Ramsey, D. K., Lamontagne, M., Xu, L., Wretenberg, P., \& Renström, P. (2006). Effect of skin movement artifact on knee kinematics during gait and cutting motions 
measured in vivo. Gait and Posture, 24(2), 152-164.

Blench, M. A. (1998). The effect of wearing work boots on lumbar spine fexion. University of Ottawa.

Böhm, H., \& Hösl, M. (2010). Effect of boot shaft stiffness on stability joint energy and muscular co-contraction during walking on uneven surface. Journal of Biomechanics, 43(13), 2467-2472.

Brown, S. H. M., \& McGill, S. M. (2010). The relationship between trunk muscle activation and trunk stiffness: examining a non-constant stiffness gain. Computer Methods in Biomechanics and Biomedical Engineering, 13(6), 829-835.

Brown, S. H. M., Vera-Garcia, F. J., \& McGill, S. M. (2006). Effects of abdominal muscle coactivation on the externally preloaded trunk: variations in motor control and its effect on spine stability. Spine, 31, E387--E393.

Bruijn, S. M., Meijer, O. G., Beek, P. J., \& van Dieën, J. H. (2010). The effects of arm swing on human gait stability. Journal of Experimental Biology, 213(23), 3945-3952.

Bruijn, S. M., van Dieën, J. H., Meijer, O. G., \& Beek, P. J. (2009). Is slow walking more stable? Journal of Biomechanics, 42(10), 1506-1512.

Callaghan, J. P., Howarth, S. J., \& Beach, T. A. C. (2011). Validation of occupational estimates of cumulative low-back load. Occupational Ergonomics, 10(3), 113-124.

Callaghan, J. P., Salewytsch, A. J., \& Andrews, D. M. (2001). An evaluation of predictive methods for estimating cumulative spinal loading. Ergonomics, 44(9), 825-837.

Chiou, S. S., Turner, N., Zwiener, J., Weaver, D. L., \& Haskell, W. E. (2012). Effect of boot weight and sole flexibility on gait and physiological responses of firefighters in stepping over obstacles. Human Factors: The Journal of the Human Factors and Ergonomics 
Society, 54(3), 373-386.

Cholewicki, J., \& McGill, S. M. (1996). Mechanical stability of the in vivo lumbar spine: Implications for injury and chronic low back pain. Clinical Biomechanics, 11(1), 1-15.

Cifrek, M., Medved, V., Tonković, S., \& Ostojić, S. (2009). Surface EMG based muscle fatigue evaluation in biomechanics. Clinical Biomechanics, 24(4), 327-340.

Cikajlo, I., \& Matjacić, Z. (2007). The influence of boot stiffness on gait kinematics and kinetics during stance phase. Ergonomics, 50(12), 2171-2182.

Coenen, P., Kingma, I., Boot, C. R. L., Bongers, P. M., \& van Dieën, J. H. (2014). Cumulative mechanical low-back load at work is a determinant of low-back pain. Occupational and Environmental Medicine, 71(5), 332-337.

Coffey, B., MacPhee, R., Socha, D., \& Fischer, S. L. (2016). A physical demands description of paramedic work in Canada. International Journal of Industrial Ergonomics, 53, 355-362.

Corlett, E. N., Eklund, J. A. E., Reilly, T., \& Troup, J. D. G. (1987). Assessment of workload from measurements of stature. Applied Ergonomics, 18(1), 65-71.

Crisco, J. J., Panjabi, M. M., Yamamoto, I., \& Oxland, T. R. (1992). Euler stability of the human ligamentous lumbar spine. Part II: Experiment. Clinical Biomechanics, 7(1), 27-32.

da Costa, B. R., \& Vieira, E. R. (2010). Risk factors for work-related musculoskeletal disorders : A systematic review of recent longitudinal studies. American Journal of Industrial Medicine, 53(3), 285-323.

Davis, K. G., \& Marras, W. S. (2000). Assessment of the relationship between box weight and trunk kinematics: does a reduction in box weight necessarily correspond to a decrease in spinal loading? Human Factors, 42(2), 195-208.

Demircan, E., Khatib, O., Wheeler, J., \& Delp, S. (2009). Reconstruction and EMG-informed 
control, simulation and analysis of human movement for athletics: performance improvement and injury prevention. Conference Proceedings: Annual International Conference of the IEEE Engineering in Medicine and Biology Society., 2009, 6534-6537. Dempsey, P. G. (1998). A critical review of biomechanical, epidemiological, physiological and psychophysical criteria for designing manual materials handling tasks. Ergonomics, 41(1), 73-88.

Donnelly, C. J., Callaghan, J. P., \& Durkin, J. L. (2009). The effect of an active lumbar system on the seating comfort of officers in police fleet vehicles. International Journal of Occupational Safety and Ergonomics, 15(3), 295-307.

Dupeyron, A., Rispens, S. M., Demattei, C., \& van Dieën, J. H. (2013). Precision of estimates of local stability of repetitive trunk movements. European Spine Journal, 22(12), 2678-2685.

Fathallah, F. A., Marras, W. S., \& Parnianpour, M. (1998). An assessment of complex spinal loads during dynamic lifting tasks. Spine, 23(6), 706-716.

Frost, D. M., Beach, T. A. C., Crosby, I., \& McGill, S. M. (2015). Firefighter injuries are not just a fireground problem. Work, 52(4), 835-842.

Gallagher, S., \& Unger, R. L. (1990). Lifting in four restricted lifting conditions. Applied Ergonomics, 21(3), 237-245.

Global Burden of Disease Study 2013 Collaborators. (2015). Global, regional, and national incidence, prevalence, and years lived with disability for 301 acute and chronic diseases and injuries in 188 countries, 1990-2013: a systematic analysis for the Global Burden of Disease Study 2013. The Lancet, 386(9995), 743-800.

Graham, R. B. (2012). Assessing dynamic spinal stability using maximum finite-time lyapunov exponents. Queens University. 
Graham, R. B., \& Brown, S. H. M. (2012). A direct comparison of spine rotational stiffness and dynamic spine stability during repetitive lifting tasks. Journal of Biomechanics, 45(9), $1593-1600$.

Graham, R. B., \& Brown, S. H. M. (2014). Local dynamic stability of spine muscle activation and stiffness patterns during repetitive lifting. Journal of Biomechanical Engineering, 136(12), 121006.

Graham, R. B., Costigan, P. A., Sadler, E. M., \& Stevenson, J. M. (2011). Local dynamic stability of the lifting kinematic chain. Gait and Posture, 34(4), 561-563.

Graham, R. B., Sadler, E. M., \& Stevenson, J. M. (2012). Local dynamic stability of trunk movements during the repetitive lifting of loads. Human Movement Science, 31(3), 592603.

Graham, R. B., Sheppard, P. S., Almosnino, S., \& Stevenson, J. M. (2012). Dynamic spinal stability and kinematic variability across automotive manufacturing work shifts and days. International Journal of Industrial Ergonomics, 42(5), 428-434.

Granata, K. P., \& England, S. A. (2006). Stability of dynamic trunk movement. Spine, 31(10), E271--E276.

Granata, K. P., \& Gottipati, P. (2008). Fatigue influences the dynamic stability of the torso. Ergonomics, 51(8), 1258-1271.

Granata, K. P., \& Marras, W. S. (1995). The influence of trunk muscle coactivity on dynamic spinal loads. Spine, 20(8), 913-919.

Granata, K. P., \& Marras, W. S. (2000). Cost-benefit of muscle cocontraction in protecting against spinal instability. Spine, 25(11), 1398-1404.

Gregory, D. E., Laughton, C., Carman, A., Milosavljevic, S., \& Callaghan, J. P. (2009). Trunk 
postures and peak and cumulative low back kinetics during upright posture sheep shearing. Ergonomics, 52(12), 1576-1583.

Hay, D. C., Wachowiak, M. P., \& Graham, R. B. (2016). Evaluating the relationship between muscle activation and spine kinematics through wavelet coherence. Journal of Applied Biomechanics, 32(5), 526-531.

Hendershot, B., Bazrgari, B., Muslim, K., Toosizadeh, N., Nussbaum, M. A., \& Madigan, M. L. (2011). Disturbance and recovery of trunk stiffness and reflexive muscle responses following prolonged trunk flexion: Influences of flexion angle and duration. Clinical Biomechanics, 26(3), 250-256.

Hodges, P. W., van den Hoorn, W., Dawson, A., \& Cholewicki, J. (2009). Changes in the mechanical properties of the trunk in low back pain may be associated with recurrence. Journal of Biomechanics, 42(1), 61-66.

Hoogendoorn, W. E., Bongers, P. M., de Vet, H. C., Douwes, M., Koes, B. W., Miedema, M. C., ... Bouter, L. M. (2000). Flexion and rotation of the trunk and lifting at work are risk factors for low back pain: results of a prospective cohort study. Spine, 25(23), 3087-3092.

Hoozemans, M. J. M., Kingma, I., de Vries, W. H. K., \& van Dieën, J. H. (2008). Effect of lifting height and load mass on low back loading. Ergonomics, 51(7), 1053-1063.

Katz, J. N. (2006). Lumbar disc disorders and low-back pain: socioeconomic factors and consequences. The Journal of Bone and Joint Surgery. American Volume, 88 Suppl 2(suppl 2), 21-24.

Kollmitzer, J., Oddsson, L. I. E., Ebenbichler, G. R., Giphart, J. E., \& De Luca, C. J. (2002). Postural control during lifting. Journal of Biomechanics, 35(5), 585-594.

Kumar, S. (1990). Cumulative load as a risk factor for back pain. Spine, 15(12), 1311-1316. 
Lavender, S. A., Andersson, G. B. J., Schipplein, O. D., \& Fuentes, H. J. (2003). The effects of initial lifting height, load magnitude, and lifting speed on the peak dynamic L5/S1 moments. International Journal of Industrial Ergonomics, 31(1), 51-59.

Majid, K., \& Truumees, E. (2008). Epidemiology and natural history of low back pain. Seminars in Spine Surgery, 20(2), 87-92.

Makhoul, P. J., Sinden, K. E., MacPhee, R. S., \& Fischer, S. L. (2017). Relative contribution of lower body work as a biomechanical determinant of spine sparing technique during common paramedic lifting tasks. Journal of Applied Biomechanics, 33(2), 137-143.

Marras, W. S., Ferguson, S. A., Burr, D., Davis, K. G., \& Gupta, P. (2004). Spine loading in patients with low back pain during asymmetric lifting exertions. Spine Journal, 4(1), 64-75.

Marras, W. S., Ferguson, S. A., Lavender, S. A., Splittstoesser, R. E., \& Yang, G. (2014). Cumulative spine loading and clinically meaningful declines in low-back function. Human Factors: The Journal of the Human Factors and Ergonomics Society, 56(1), 29-43.

Mathiassen, S. E., Winkel, J., \& Hägg, G. M. (1995). Normalization of surface EMG amplitude from the upper trapezius muscle in ergonomic studies - a review. Journal of Electromyography and Kinesiology, 5(4), 197-226.

Mavor, M. P., \& Graham, R. B. (2015). Exploring the relationship between local and global dynamic trunk stabilities during repetitive lifting tasks. Journal of Biomechanics, 48(14), $3955-3960$.

Mc Kinnon, C. D., Callaghan, J. P., \& Dickerson, C. R. (2011). Field quantification of physical exposures of police officers in vehicle operation. International Journal of Occupational Safety and Ergonomics, 17(1), 61-68.

McGill, S. M. (1992). A myoelectrically based dynamic three-dimensional model to predict 
loads on lumbar spine tissues during lateral bending. Journal of Bomechanics, 25(4), 395414.

McGill, S. M., \& Brown, S. (1992). Creep response of the lumbar spine to prolonged full flexion. Clinical Biomechanics, 7(1), 43-46.

Mehta, J. P., Lavender, S. A., \& Jagacinski, R. J. (2014). Physiological and biomechanical responses to a prolonged repetitive asymmetric lifting activity. Ergonomics, 57(4), 575588.

Norman, R., Wells, R., Neumann, P., Frank, J., Shannon, H., Kerr, M., ... Woo, H. (1998). A comparison of peak vs cumulative physical work exposure risk factors for the reporting of low back pain in the automotive industry. Clinical Biomechanics, 13(8), 561-573.

Oddsson, L. I. E., Persson, T., Cresswell, A. G., \& Thorstensson, A. (1999). Interaction between voluntary and postural motor commands during perturbed lifting. Spine, 24(6), 545-552.

Panjabi, M. M. (1992a). The stabilizing system of the spine. Part I. Function, dysfunction, adaptation, and enhancement. Journal of Spinal Disorders, 5(4), 383--389; discussion 397.

Panjabi, M. M. (1992b). The stabilizing system of the spine. Part II. Neutral zone and instability hypothesis. Journal of Spinal Disorders, 5(4), 390-6; discussion 397.

Park, W., Singh, D. P., Huston, R. L., \& Song, S. (2008). A quantitative method for representing balance strategies of goal-directed human motions. Computers in Biology and Medicine, 38(10), 1094-1102.

Racinais, S., \& Oksa, J. (2010). Temperature and neuromuscular function. Scandinavian Journal of Medicine and Science in Sports, 20(SUPPL. 3), 1-18.

Radwin, R. G., Marras, W. S., \& Lavender, S. A. (2002). Biomechanical aspects of work-related musculoskeletal disorders. Theor. Issues In Ergon. Sci., 2(2), 153-217. 
Reeves, N. P., \& Cholewicki, J. (2013). Spine systems science: a primer on the systems approach. In Spinal Control: The Rehabilitation of Back Pain: State of the art and science (pp. 7-16). China: Elsevier.

Robertson, D. G. E., Caldwell, G. E., Hamill, J., Kamen, G., \& Whittlesey, S. N. (2014). Research Methods in Biomechanics (2nd ed.). Champaign, Illinois: Human Kinetics.

Rosenstein, M. T., Collins, J. J., \& De Luca, C. J. (1993). A practical method for calculating largest Lyapunov exponents from small data sets. Physica D: Nonlinear Phenomena, 65(12), 117-134.

Ross, G. B., Mavor, M. P., Brown, S. H. M., \& Graham, R. B. (2015). The effects of experimentally induced low back pain on spine rotational stiffness and local dynamic stability. Annals of Biomedical Engineering, 43(9), 2120-2130.

Russell, S. J., Winnemuller, L., Camp, J. E., \& Johnson, P. W. (2007). Comparing the results of five lifting analysis tools. Applied Ergonomics, 38(1), 91-97.

Sadler, E. M., Graham, R. B., \& Stevenson, J. M. (2011). The personal lift-assist device and lifting technique: a principal component analysis. Ergonomics, 54(4), 392-402.

Sadler, E. M., Graham, R. B., \& Stevenson, J. M. (2013). Gender difference and lifting technique under light load conditions: a principal component analysis. Theoretical Issues in Ergonomics Science, 14(2), 159-174.

Sheppard, P. S., Stevenson, J. M., \& Graham, R. B. (2016). Sex-based differences in lifting technique under increasing load conditions: A principal component analysis. Applied Ergonomics, 54, 186-195.

Shourijeh, M. S., Smale, K. B., Potvin, B. M., \& Benoit, D. L. (2016). A forward-muscular inverse-skeletal dynamics framework for human musculoskeletal simulations. Journal of 
Biomechanics, 49(9), 1718-1723.

Snook, S. H., \& Ciriello, V. M. (1991). The design of manual handling tasks: revised tables of maximum acceptable weights and forces. Ergonomics, 34(9), 1197-1213.

Solomonow, M. (2012). Neuromuscular manifestations of viscoelastic tissue degradation following high and low risk repetitive lumbar flexion. Journal of Electromyography and Kinesiology, 22(2), 155-175.

Statistics Canada (2010a). Trends in the Trades: Registered Apprenticeship Registrations, Completions and Certification, 1991 to 2007. http://www.statcan.gc.ca/pub/81-004x/2009006/article/11127-eng.htm\#d

Statistics Canada (2010b). Women in Non-traditional Occupations and Fields of Study. http://www.statcan.gc.ca/pub/81-004-x/2010001/article/11151-eng.htm

Toebes, M. J. P., Hoozemans, M. J. M., Dekker, J., \& van Dieën, J. H. (2014). Effects of unilateral leg muscle fatigue on balance control in perturbed and unperturbed gait in healthy elderly. Gait \& Posture, 40(1), 215-219.

Toosizadeh, N. (2013, February). Time-dependent assessment of the human lumbar spine in response to flexion exposures: in vivo measurement and modeling. Virginia Polytechnic Institute and State University.

van Dieën, J. H., Cholewicki, J., Radebold, A., van Dieën, J. H., Cholewicki, J., \& Radebold, A. (2003). Trunk muscle recruitment patterns in patients with low back pain enhance the stability of the lumbar spine. Spine, 28(8), 834-841.

van Dieën, J. H., \& Kingma, I. (1999). Total trunk muscle force and spinal compression are lower in asymmetric moments as compared to pure extension moments. Journal of Biomechanics, 32(7), 681-687. 
van Dieën, J. H., Weinans, H., \& Toussaint, H. M. (1999). Fractures of the lumbar vertebral endplate in the etiology of low back pain: a hypothesis on the causative role of spinal compression in aspecific low back pain. Medical Hypotheses, 53(3), 246-252.

Walker, B. F. (2000). The prevalence of low back pain: a systematic review of the literature from 1966 to 1998. Journal of Spinal Disorders, 13(3), 205-217.

Waters, T. R., Baron, S. L., \& Kemmlert, K. (1998). Accuracy of measurements for the revised NIOSH lifting equation. Applied Ergonomics, 29(6), 433-438.

Waters, T. R., Lu, M.-L., Piacitelli, L. A., Werren, D., \& Deddens, J. A. (2011). Efficacy of the revised NIOSH lifting equation to predict risk of low back pain due to manual lifting. Journal of Occupational and Environmental Medicine, 53(9), 1061-1067.

Waters, T. R., Putz-Anderson, V., Garg, A., \& Fine, L. J. (1993). Revised NIOSH equation for the design and evaluation of manual lifting tasks. Ergonomics, 36(7), 749-776.

Work Safe BC (2017). Personal protective clothing and equipment. https://www.worksafebc.com/en/law-policy/occupational-health-safety/searchable-ohsregulation/ohs-regulation/part-08-personal-protective-clothing-and-equipment

Workplace Safety and Insurance Board of Ontario (2016). WSIB by the numbers 2016. http://www.wsib.on.ca/

Workplace Safety North (2017). MSD prevention guideline for Ontario. https://www.workplacesafetynorth.ca/subsite/msds-priority-hazards/msd-preventionguideline-ontario 


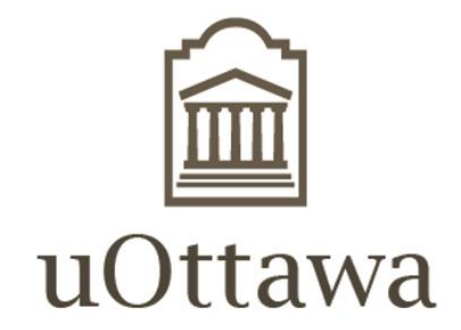

Université d'Ottawa

Faculté des sciences de la santé

École des sciences de l'activité physique

University of Ottawa

Faculty of Health

Sciences

School of Human Kinetics

\section{Appendix A \\ Research Consent Form}

\section{Research Project Title: The effects of protective footwear on mechanical spine loading and control during lifting.}

Principal Investigators:

Matthew Mavor

Dr. Ryan Graham

University of Ottawa

Faculty of Health Sciences

Department of Human Kinetics

\section{Background and Purpose of the Study:}

Low back injuries are common events that affect all ages, occupations, and sexes. Manual materials handling $(\mathrm{MMH})$ is regarded as one of the largest risk factors for developing a low back injury. Many occupations where $\mathrm{MMH}$ is common are in hazardous environments, requiring workers to wear personal protective equipment (PPE). The most commonly prescribed form of PPE are CSA Grade 1 work boots. Work boots are designed to protect the foot from crushing and puncturing hazards; however, they inadvertently affect human movement by reducing ankle range of motion, promoting greater spine flexion while lifting. Therefore, the goal of this research is to investigate the link between protective footwear and low back injury risk while performing repetitive lifts at the flexion end-range (lifting from the floor to waist height). Low back injury risk will be evaluated using spinal loading and local dynamic stability.

\section{Description of Study Procedures:}

You are invited to participate in a one-day motion analysis procedure for approximately 2.5 hours at the University of Ottawa Human Movement Biomechanics Laboratory (200 Lees Avenue, E020). The study protocol consists of two blocks of a repetitive lifting task. For both blocks, you will perform repetitive lifts at the flexion end-range (floor to waist height) under three randomly assigned footwear conditions (work boots laced to ankle height, work boots fully laced, and fully laced work boots with a metatarsal guard). A total of 6 movement trials will be performed ( 3 footwear conditions x 1 posture $\mathrm{x} 1$ load $=3$ movement trials $\mathrm{x} 2$ blocks $=6$ movement trials). In an attempt to reduce fatigue, you will be given 5 minutes rest between each movement trial. Pain and fatigue levels will be monitored on a visual analogue scale.

In block 1, you will perform 5 repetitive lifts (at your preferred lifting speed) of a load that is equal to $20 \%$ of your maximum back strength; determined by pulling against a uniaxial load cell (PY6, Bertec Corporation, USA). 
In block 2, you will perform 30 repetitive lifts (controlled through a metronome; 6 lift cycles/minute) of a load that is equal to $10 \%$ of your maximum back strength.

Upon arrival, you will be asked to change into a custom-designed spandex body suit. Your skin will be shaven and cleaned with alcohol in preparation for the placement of electromyography (EMG) electrodes on 6 muscles bilaterally: external oblique (EO), internal oblique (IO), rectus abdominis (RA), lumbar erector spinae (LES), thoracic erector spinae (TES), and latissimus dorsi (LAT). After the EMG electrodes are adhered to the muscle bellies with double sided tape, you will be asked to perform maximal voluntary contractions (MVCs) for all the muscles to be studied. These MVC trials will consist of resisted sit-ups, resisted back extensions, and resisted lat pulldowns. After all MVC trials are completed, individual markers will be placed on specific bony landmarks and marker clusters will be placed on limb segments, for the purpose of video and motion capture. Before the experimental trials can begin, you will be asked to perform two fivesecond static reference calibration trials to create an individualized biomechanical model, and a loaded (20kg) $45^{\circ}$ trunk flexion trial. After these static/loaded trials are complete, some individual markers will be removed, and the experimental trials will begin.

\section{Possible Risks and Discomforts:}

There are no significant risks associated with participating in this study. You may experience pain and fatigue due to the nature of the lifting tasks. However, sufficient rest will be given to reduce these effects. To attach the EMG electrodes, areas of skin on the abdominals and back may need to be shaved and will be cleaned with alcohol. The tape used to attach the EMGs may cause minor skin irritation; similar to what it experienced with a bandage and typically fades within 2 to 3 days.

Should you experience any major discomfort, please tell us immediately and seek primary care from a medical professional on campus (100 Marie Curie, Ottawa, Tel.: 613-564-3950) or a medical professional of your choosing.

\section{Possible Benefits:}

You will not directly benefit from participating in this study. However, the results of this study will greatly add to our knowledge of how footwear affects spine biomechanics during lifting tasks.

\section{Voluntary Participation:}

You are not obliged to participate in this study; participation in this study is voluntary. You may also withdraw from the study at any time with no penalty or coercion. You will be compensated up to the time of withdrawal.

\section{Confidentiality:}

All personal information is kept confidential unless release is required by law. Information gained from this study will be stored electronically and will need a password to access. Paper study records are stored in a locked cabinet and will be destroyed after 5 years; electronic records will be deleted and paper records will be shredded. You will not be identified by name in any reports of the completed study. Your anonymity will be strictly maintained - you will not be identified by your name, but will be determined by an independent study number.

\section{Compensation:}

You will receive $\$ 20$ in compensation for your participation in this study. 


\section{Questions about the Study:}

You are free to ask questions at any time. This protocol has been approved by the University of Ottawa research ethics board. If you have any questions regarding the ethical conduct of this study, you may contact the Protocol Officer for Ethics in Research, University of Ottawa, Tabaret Hall, 550 Cumberland Street, Room 154, Ottawa ON, K1N 6N5. Tel.: (613) 562-5387 Email: ethics@uottawa.ca 


\section{Research Project Title: The effects of footwear on mechanical spine loading and control during lifting.}

\section{Consent:}

I have read this consent form, and I agree to participate in the procedures of this study.

Printed Name of Participant

Signature of Participant

Date

\section{Investigator Statement (or Person Explaining the Consent):}

I have carefully explained to the research participant the nature of the above research study. To the best of my knowledge, the research participant signing this consent form understands the nature, demands, risks and benefits involved in participating in this study. I acknowledge my responsibility for the care and well-being of the above research participant, to respect the rights and wishes of the research participant, and to conduct the study according to applicable Good Clinical Practice guidelines and regulations.

Name of Investigator/Delegate (printed)

Signature of Investigator/Delegate

Date

\section{Informed Consent to have Pictures Taken:}

I consent to have side view pictures taken of myself completing the experiment, and understand that no pictures will be taken at any point without me knowing. I also understand that if any of these pictures are used in a subsequent presentation or publication, that my face and any other identifiers will be blurred. You can still participate in the research study without consenting to have pictures taken.

Name

Date

Signature

Witness Name

Witness Signature

\section{Future Participation:}

I am interested in being contacted to participate in future research performed by this laboratory (your email information will be saved in a password protected file). 


\section{Formulaire d'information et de consentement à a la recherche}

\section{uOttawa}

Université d'Ottawa

Faculté des sciences de la santé

École des sciences de l'activité physique

University of Ottawa

Faculty of Health

Sciences

School of Human Kinetics
Titre du projet de recherche :

\author{
Les effets dû au port de souliers de \\ protection sur la colonne vertébrale et le \\ contrôle lors de la levée de charge. (Version \\ française de The effects of protective footwear \\ on mechanical spine loading and control \\ during lifting.)
}

Personnes responsables du projet:

Matthew Mavor
Dr. Ryan Graham
Université d'Ottawa

Faculté des sciences de la santé

École des sciences de l'activité physique

\section{Informations reliées au projet et objectif de l'étude :}

La lombalgie (douleur au bas du dos) est une condition commune qui affecte tous les différents groupe d'âge, sexes et occupations. Le maniement de matériel est reconnu comme étant un des plus grand facteurs de risque menant au développement de la lombalgie. Dans plusieurs professions, le maniement de matériel est une pratique commune. Souvent dans des environnements dangereux, il requiert de la part des travailleurs qu'ils se munissent d'équipement de protection personnel. La botte de travail CSA Grade 1 est celle la forme de protection personnelle la plus souvent prescrite.

Il est faite de sorte qu'elle puisse protéger le pied contre l'écrasement ou la perforation par un objet dangereux. Par contre, par inadvertance, elle affecte le mouvement humain en réduisant l'amplitude de la cheville, causant une plus grande flexion de la colonne vertébrale lors de la levée de charge. Ceci étant dit, le but de cette recherche est d'investiguer le lien entre la port de souliers de protection et le risque de lombalgie lors de la levée de charge répétitive en flexion soit du sol au niveau des hanches. Les risques de lombalgie seront estimés par l'évaluation de la charge sur la colonne vertébrale et de la stabilité dynamique locale.

\section{Description des procédures de l'étude :}

Le protocole de cette étude requiert la levée répétitive de deux blocs. Pour chaque blocs, vous aurez a exécuter des levées de charge répétitive en flexion, soit du sol au niveau des hanches, en portant les souliers qui vous seront aléatoirement assignés (i.e. bottes de travail lacées jusqu'à la cheville, bottes de travail complètement lacées ou bottes de travail complètement lacées et munies d'un protecteur métatarsien). Un total de 6 mouvements seront exécutés $(3$ sortes de souliers $\mathrm{x} 1$ posture $\mathrm{x} 1$ charge $=$ 3 mouvements $\mathrm{x} 2$ blocs $=6$ mouvements au total). Dans le but de réduire le niveau de fatigue, vous bénéficierez de 5 minutes de pause en chaque mouvement effectué. Les niveau de douleur de fatigue seront surveillées grâce à une échelle visuelle analogique. 
Dans le premier bloc, yous effectuerez 5 levées répétitives (à la vitesse de votre choix) d'une masse équivalente à $20 \%$ de votre force dorsale maximale qui elle sera prédéterminée en tirant sur un capteur de force uniaxial (PY6, Bertec Corporation, USA).

Dans le second bloc, yous effectuerez 30 levée répétitives (au rythme du métronome; 6 cycle de levée/minute) d'une masse équivalente à $10 \%$ de votre force dorsale maximale.

À votre arrivée, vous serez demandé de vous changer et de mettre un ensemble de Spandex spécialement conçu pour l'analyse du mouvement. Votre peau sera rasée et nettoyée avec de l'alcool en préparation pour le placement bilatéral d'électrodes d'électromyographie (EMG) sur 6 muscles : l'oblique externe, l'oblique interne, le muscle droit de l'abdomen, les muscles érecteurs du rachis soit le lombaire et le thoracique et le grand dorsal. Une fois que les électrodes auront bien adhérées à la peau sur le ventre du muscle à l'aide de ruban adhésif double face, il vous sera demandé d'effectuer des contractions musculaires volontaires pour s'assurer que tous les muscles puissent être étudiés. Contre de la résistance, des redressements assis, des extensions dorsales et des abaissements latéraux seront effectué pour générer les contractions. Suite à ces contractions, des marqueurs individuels seront apposés sur des repères osseux spécifiques et un ensemble de marqueurs sera placé sur les membres dans le but d'utiliser l'équipement de capture de mouvement par vidéo. Préalablement au début de l'expérience, il vous sera demandé d'effectuer deux calibrations statiques de 5 secondes pour générer un modèle biomécanique individualisé pour les essais à suivre. La calibration statique sera suivie d'une calibration dynamique, soit une flexion des hanches à $45^{\circ}$ avec un poids de $20 \mathrm{~kg}$. À la suite des essais de calibration, certains marqueurs individuels seront enlevés et l'expérience débutera.

\section{Risques et inconforts possibles :}

La participation à cette étude ne présente pas de risque significatif. Vous pourriez ressentir certaines douleurs et/ou de la fatigue dû à la nature de la tâche effectuée. Cependant, un temps de repos suffisant vous sera accordé pour en réduire les effets. Pour apposer les électrodes d'électromyographie, de petites surfaces de peau sur les abdominaux et le dos devront peut-être être rasés et nettoyés avec de l'alcool. Le ruban adhésif utilisé pour maintenir les électrodes en places peut engendrer de légères irritations cutanées, similaires à celles causées par un pansement. De telles irritations devraient se résorber en 2 à 3 jours.

S'il advenait que vous ressentiez des inconforts majeurs, laissez-nous le savoir le plus rapidement possible pour que nous puissions vous procurer l'aide médicale nécessaire à même le campus (100 rue Marie-Curie, Ottawa, Tel. : 613-564-3950) ou à l'endroit de votre choix.

\section{Avantages possibles :}

Vous ne bénéficierez d'aucun avantage direct en participant à cette étude. Toutefois, les résultats qui en ressortiront vont grandement contribuer à enrichir nos connaissances sur la façon dont le port de soulier peut affecter la biomécanique de la colonne vertébrale lors de la levée d'une charge.

\section{Participation volontaire :}

Vous n'êtes en aucun cas obligé de participer à cette étude. La participation est sur une base volontaire. Vous pouvez aussi vous retirer de l'étude à tout moment sans aucune pénalité ou coercition. Vous recevrez une compensation calculée en fonction de votre temps de participation à l'étude avant votre retrait.

\section{Confidentialité :}

Votre information personnelle sera tenue confidentielle sauf si sa divulgation est légalement obligatoire. L'information recueillie lors de l'étude sera stockée électroniquement et son accès nécessitera un mot de passe. Les données format papier de l'étude seront rangées dans un casier barré. Les données sur format papier seront détruites à la déchiqueteuse et les données électroniques seront supprimées 5 ans après la fin 
de l'étude. Vous ne serez en aucun cas identifié par votre nom dans les rapports finaux de l'étude. Votre anonymat sera maintenu - vous ne serez pas identifié par votre nom et votre cas sera associé à un numéro d'étude indépendant.

\section{Compensation :}

Vous recevrez une compensation monétaire de $20 \$$ pour votre participation à cette étude.

\section{Questions en lien avec l'étude :}

Vous êtes libres de poser des questions en tout temps. Ce protocole a reçu l'approbation du comité d'éthique de l'Université d'Ottawa. Si vous avez de questions concernant le protocole éthique de cette étude, vous pouvez contacter la Responsable d'éthique en recherche, Université d'Ottawa, Pavillon Tabaret, 550 rue Cumberland, Salle 154, Ottawa ON, K1N 6N5. Tel. : (613) 562-5387 Email : ethics@ uottawa.ca 
Titre du projet de recherche :

Les effets dû au port de souliers de protection sur la colonne vertébrale et le contrôle lors de la levée de charge.

\section{Consentement :}

J'ai lu ce formulaire de consentement et j'accepte de participer aux procédures entourant ce projet de recherche.

Nom du participant entre lettres moulées

Signature du participant

Date

Déclaration de la personne responsable (ou de la personne en charge d'expliquer le consentement) : J'ai fait attention d'expliquer clairement la nature de cette recherche au participant de l'étude. Au meilleur de mes connaissances, le participant qui signe ce formulaire de consentement comprend, la nature, les exigences, les risques ainsi que les avantages en lien avec la participation à cette étude. Je suis conscient de la responsabilité que j'ai de prendre soins et d'assurer le bien-être du participant ci-dessus, de respecter ces droits et demandes et d'effectuer cette étude en en respectant les normes et règlements entourant les Bonnes pratiques cliniques.

Nom de la personne responsable/Délégué en lettres moulées

Signature de la personne responsable/Délégué en lettres moulées

\section{Consentement à la prise de photo :}

Je consens à avoir des photos de moi prises de côté lorsque je serai entrain de compléter l'étude et je comprends qu'en aucun cas elles seront prises sans en avoir été averti préalablement. Je comprends aussi que si ces photos sont utilisées dans des publications subséquentes, mon visage et autres identifiants seront brouillés. Si vous ne consentez pas à la prise de photos, vous pouvez tout de même participer à cette étude.

Nom du participant entre lettres moulées

Signature du participant

Date

Nom du témoin entre lettres moulées

Signature du témoin

\section{Participations futures :}

Je suis intéressé à être contacté pour des recherches futures dans ce laboratoire (votre adresse courriel sera sauvegardé dans un dossier accessible avec un mot de passe) 


\section{$\underline{\text { Appendix B }}$ \\ Footwear Marker Placement}
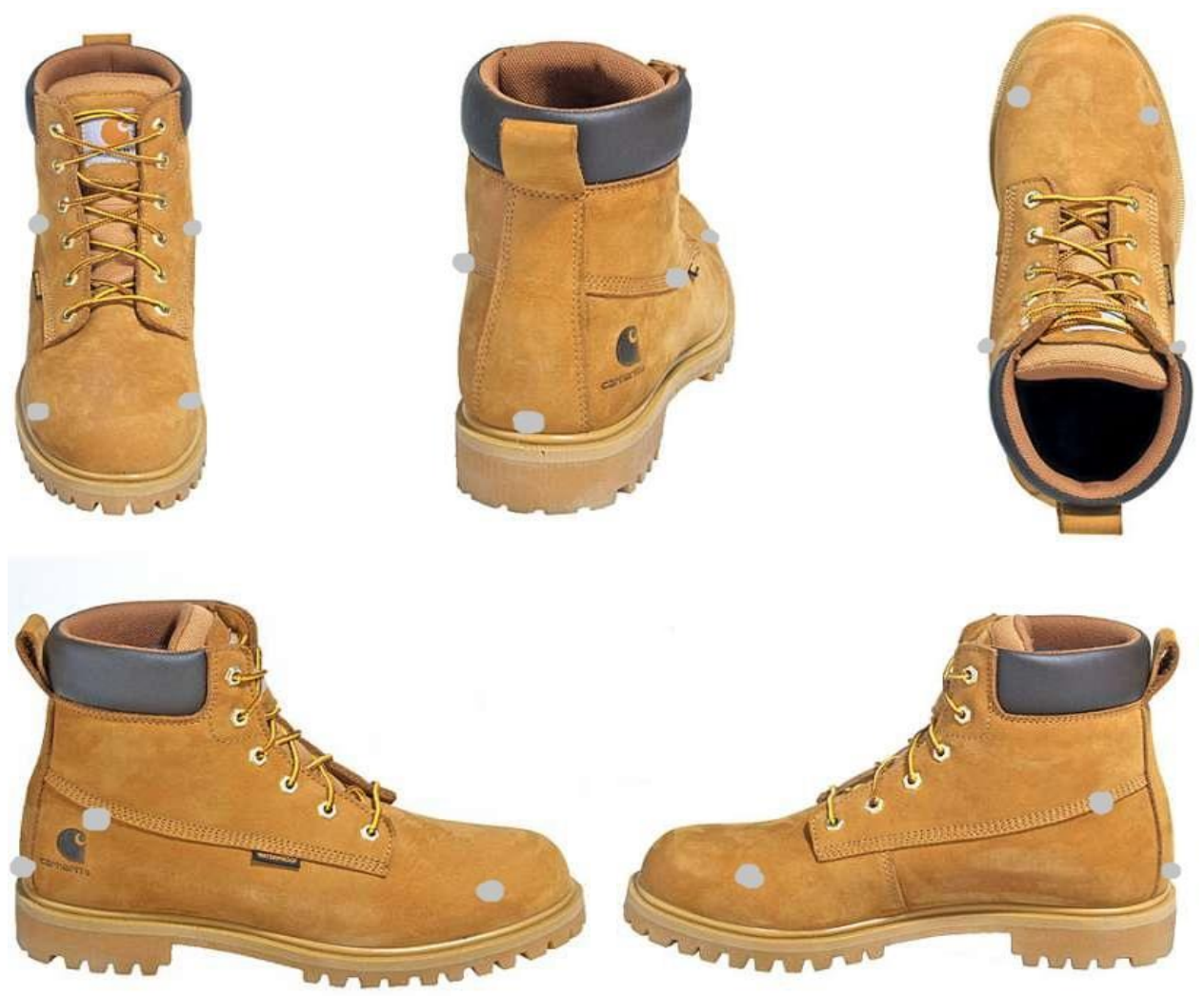

Figure B1. Marker placement to track the feet in work boots. Grey circles represent individual markers on the 1st and 5th metatarsals, calcaneus, and medial and lateral malleoli. Markers were adhered to the boot using double sided tape. 


\section{Appendix C}

\section{Marker Placement}

\begin{tabular}{|c|c|c|c|}
\hline Segment & Placement & Name & Use \\
\hline \multirow{4}{*}{ Head } & Front right & RFHD & Calibrate/Track Head \\
\hline & Front left & LFHD & Calibrate/Track Head \\
\hline & Back right & RBHD & Calibrate/Track Head \\
\hline & Back left & LBHD & Calibrate/Track Head \\
\hline \multirow{3}{*}{$\begin{array}{l}\text { Upper Arm } \\
\text { (Bilateral) }\end{array}$} & $\begin{array}{l}\text { Humerus Lateral } \\
\text { Epicondyle }\end{array}$ & LELBL/RELBL & $\begin{array}{l}\text { Calibrate Upper arm and Forearm } \\
\text { width }\end{array}$ \\
\hline & $\begin{array}{l}\text { Humerus Medial } \\
\text { Epicondyle }\end{array}$ & LELBM/RELBM & $\begin{array}{l}\text { Calibrate Upper arm and Forearm } \\
\text { width }\end{array}$ \\
\hline & Cluster: Middle, lateral & $\begin{array}{l}\text { LUAPP, LUAPA, LUADA, LUADP/ RUAPP, } \\
\text { RUAPA, RUADA, RUADP }\end{array}$ & Track upper arm segment \\
\hline \multirow{3}{*}{$\begin{array}{l}\text { Forearm } \\
\text { (Bilateral) }\end{array}$} & Ulna & LULN & Calibrate Forearm width \\
\hline & Radius & LRAD & Calibrate Forearm width \\
\hline & Cluster: Middle, Lateral & $\begin{array}{l}\text { LFAPP, LFAPA, LFADA, LFADP/ RFAPP, } \\
\text { RFAPA, RFADA, RFADP }\end{array}$ & Track forearm segment \\
\hline \multirow{8}{*}{ Trunk } & Sternal Notch & SN & Calibrate Trunk Depth \\
\hline & Xiphoid & $\mathrm{XP}$ & Calibrate Trunk Depth \\
\hline & Left Acromion & LAC & $\begin{array}{c}\text { Calibrate Trunk Depth/ Track Upper } \\
\text { Back }\end{array}$ \\
\hline & Right Acromion & RAC & $\begin{array}{l}\text { Calibrate Trunk Depth/ Track Upper } \\
\text { Back }\end{array}$ \\
\hline & Left Scapula & LSCAP & $\begin{array}{c}\text { Calibrate Trunk Depth/ Track Upper } \\
\text { Back }\end{array}$ \\
\hline & Right Scapula & RSCAP & $\begin{array}{c}\text { Calibrate Trunk Depth/ Track Upper } \\
\text { Back }\end{array}$ \\
\hline & $\mathrm{C} 7$ & $\mathrm{C} 7$ & Track Upper Back \\
\hline & $\begin{array}{c}\text { Cluster: } \mathrm{T} 10 / \mathrm{T} 12 \\
\text { vertebrae }\end{array}$ & LBUL, LBUR, LBLL, LBLR & Track Low Back segment \\
\hline \multirow{7}{*}{ Pelvis } & Left ASIS & LASI & Calibrate Pelvis width/depth \\
\hline & Right ASIS & RASI & Calibrate Pelvis width/depth \\
\hline & Left PSIS & LPSI & Calibrate Pelvis width/depth \\
\hline & Right PSIS & RPSI & Calibrate Pelvis width/depth \\
\hline & Left Iliac Crest & LIC & Calibrate Trunk width \\
\hline & Right Iliac Crest & RIC & Calibrate Trunk width \\
\hline & Cluster: Sacrum & PVUL, PVUR, PVLL, PVLR & Track Pelvis \\
\hline \multirow{4}{*}{ Thigh (Bilateral) } & Greater Trochanter & LGT/RGT & Calibrate Thigh width, length \\
\hline & Lateral Femur Epicondyle & LKNL/RKNL & Calibrate Thigh/Shank width, length \\
\hline & Medial Femur Epicondyle & LKNM/RKNM & Calibrate Thigh/Shank width, length \\
\hline & $\begin{array}{l}\text { Cluster: Middle; lateral } \\
\text { side }\end{array}$ & $\begin{array}{l}\text { LTHPA, LTHPP, LTHDA, LTHDP/ RTHPA, } \\
\text { RTHPP, RTHDA, RTHDP }\end{array}$ & Track Thigh \\
\hline Shank (Bilateral) & $\begin{array}{l}\text { Cluster: Middle; lateral } \\
\text { side }\end{array}$ & $\begin{array}{l}\text { LSHPA, LSHPP, LSHDA, LSHDP/ RSHPA, } \\
\text { RSHPP, RSHDA, RSHDP }\end{array}$ & Track Shank \\
\hline \multirow{5}{*}{ Foot (Bilateral) } & Lateral Malleolus & LANL/RANL & $\begin{array}{l}\text { Calibrate Shank width, length/Foot } \\
\text { width/Track Foot }\end{array}$ \\
\hline & Medial Malleolus & LANM/RANM & $\begin{array}{l}\text { Calibrate Shank width, length/Foot } \\
\text { width }\end{array}$ \\
\hline & $\begin{array}{l}\text { 1st Metatarsophalangeal } \\
\text { joint }\end{array}$ & LM1/RM1 & $\begin{array}{l}\text { Calibrate Foot width, length/ Track } \\
\text { foot }\end{array}$ \\
\hline & $\begin{array}{l}\text { 5th Metatarsophalangeal } \\
\text { joint }\end{array}$ & LM5/RM5 & $\begin{array}{l}\text { Calibrate Foot width, length/ Track } \\
\text { foot }\end{array}$ \\
\hline & Calcaneus & LHEE/RHEE & Calibrate Foot length/ Track foot \\
\hline
\end{tabular}




\section{Appendix D}

\section{Sample Data}

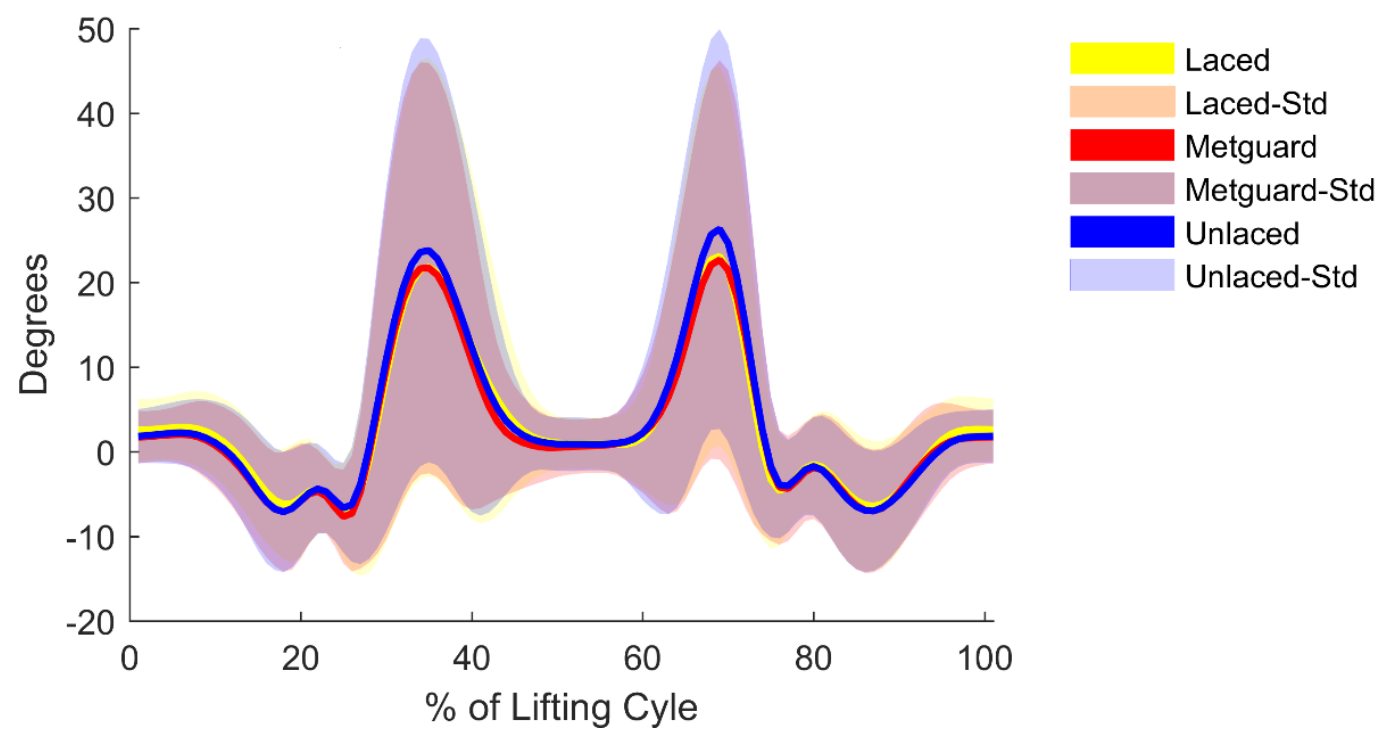

Figure D1. Sample data of ankle dorsiflexion. Data across the 30 lifts were averaged within participants and then ensemble averaged to represent a mean lifting cycle for each condition. Std $=$ standard deviation clouds. Dorsiflexion = positive; plantar flexion = negative .

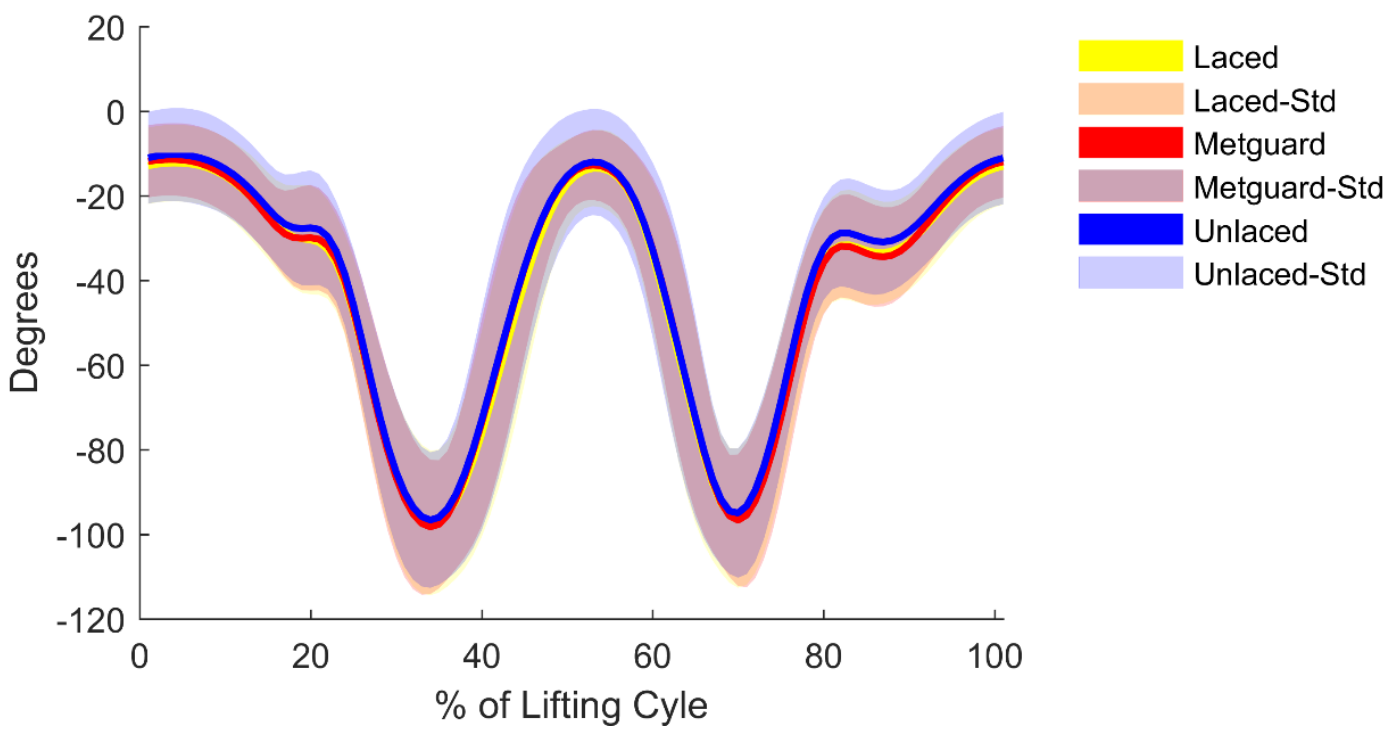

Figure D2. Sample data of low back flexion angles. Data across the 30 lifts were averaged within participants and then ensemble averaged to represent a mean lifting cycle for each condition. Std $=$ standard deviation clouds. Lumbar extension = positive; lumbar flexion = negative. 


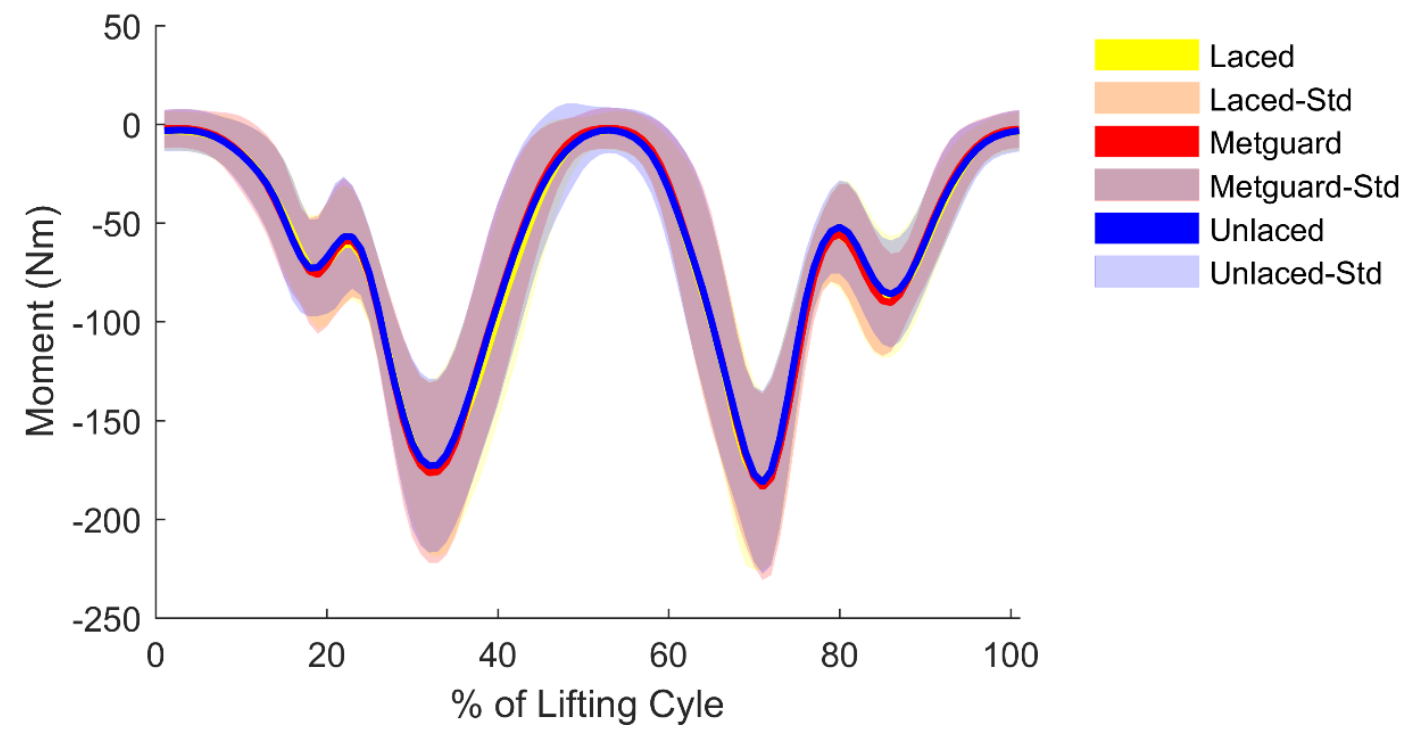

Figure D3. Sample data of low back sagittal moments. Data across the 30 lifts were averaged within participants and then ensemble averaged to represent a mean lifting cycle for each condition. Std = standard deviation clouds. Extension moment $=$ positive; flexion moment $=$ negative. 